\title{
ESTILO DE SEVIR A PRINCIPES. LA COCINA Y LA MESA DE UN GRANDE DE ESPAÑA EN EL SIGLO DE ORO
}

\author{
María de los Ángeles Pérez Samper \\ Universidad de Barcelona
}

\section{$\underline{R E S U M E N}$}

En el siglo XVII, siguiendo el ejemplo de la corte, el estilo de vida aristocrático llegaria a adquirir en Españá un elevado grado de refinamiento. El lujo, el ceremonial, las maneras depuradas se convirtieron en señales claras de poder, honor y prestigio. La alimentación puede resultar un buen parámetro para conocer el modelo de vida de la nobleza. Por ello resulta muy ilustrativa la obra de Yelgo de Bázquez, Estilo de servir a principes, dedicada al Duque de Uceda y publicada en Madrid en 1614, que proporciona abundante información sobre el servicio de una gran casa.

Palabras clave: Nobleza, alimentación, España, siglo XVII.

\section{$\underline{A B S T R A C T}$}

In the XVII century, following the example of the court, the aristocratic life style in Spain reached a high level of refinement. The luxury, the ceremony, the polite manners became clear signals of power, honour and prestige. Diet could be a good indicator to know more about the aristocratic way of life. The work of Yelgo Bázquez, Estilo de servir a principes, dedicated to the Duque of Uceda, would be excellent for this purpose since the work contains abudant information about the service and housekeeping in a noble household.

Keywords: Nobility, feeding, Spain, XVII ${ }^{\text {th }}$ century.

Ser noble no era sólo cuestión de sangre, de linaje, de títulos o de patrimonio. Ser noble suponía necesariamente vivir como un noble. Es indiscutible, como afirma Don Antonio Domínguez Ortiz, que existía un tipo de vida noble, que se manifestaba lo mismo en la mentalidad, ocupaciones y hábitos que en los detalles materiales de la existencia. Pero ese estilo de vida noble no siempre era el mismo, fue evolucionando a lo largo de los siglos. Como señala el mismo autor, el carácter indómito y bravío de la nobleza medieval todavía se manifestaba en el siglo $X V I$, al menos en aquella que no había sido aun domesticada por la dorada servidumbre de la Corte. En la gradual transformación de las costumbres nobiliarias 
hacia moldes más pulidos y maneras más corteses influyeron causas muy diversas, la instalación en las ciudades, la diferenciación entre una nobleza más establecida y sedentaria y otra más inquieta, lanzada a la vida aventurera en los campos de batalla del Viejo y el Nuevo Mundo, la forzosa integración en un mundo de valores, que no era ya el del puro dinamismo individual, sino el modelo ceremonial de la Corte de los Habsburgos. En opinión de Domínguez Ortiz, el rígido aparato de poder dirigido por Felipe II tuvo como una de sus principales tareas la de amansar a una nobleza, en algunos aspectos algo cerril ${ }^{1}$. En el siglo XVII, siguiendo el modelo de la nobleza cortesana, el estilo de vida aristocrático llegaría a adquirir en España un elevado grado de refinamiento. El lujo, el ceremonial, las maneras depuradas se convirtieron en señales claras de poder, honor y prestigio.

En este sentido el tema alimentario puede resultar un buen parámetro para conocer mejor en qué consistía y cómo se desarrollaba el modelo de vida de la nobleza. La abundancia de comida y bebida, la calidad de los productos, la excelencia de su preparación culinaria, la capacidad de elegir sin limitaciones, la satisfacción de los gustos y caprichos, la complicación y sofisticación del ceremonial, con los pajes sirviendo los platos a sus señores de rodillas y los gentilhombres haciendo reverencias a la copa del señor, son buenos indicios de la imagen ideal de riqueza, poder y privilegio que el noble pretendia encarnar y ofrecer a la sociedad, incluso en el ámbito privado de su casa y en la vida diaria, mucho más cuando se trataba de un acto de mayor trascendencia y con mayor audiencia, en ocasión, por ejemplo, de banquetes, fiestas y celebraciones. ${ }^{2}$

Para aproximarnos a la organización de la alimentación, al servicio de la cocina y al ceremonial de la mesa que se estilaría en una casa de la alta nobleza española de los siglos XVI y XVII resulta muy ilustrativa la obra de Yelgo de Bázquez, Estilo de servir a príncipes, dedicada al Duque de Uceda y publicada en Madrid en 1614, que proporciona abundante información sobre el servicio de una gran casa ${ }^{3}$. Manifiesta como objetivo en el prólogo enseñar el modo de servir a un Príncipe o a un Grande de España, a usanza española. Naturalmente este tratado no sabemos hasta qué punto fue practicado verdaderamente en las grandes casas nobiliarias $o$, al menos, en alguna de ellas. Pero el simple hecho de haber sido escrito ya resulta indicativo de las ideas existentes en la época sobre el

\footnotetext{
' DOMINGUEZ ORTIZ, Antonio: Las clases privilegiadas en la España del Antiguio Réginten, Madrid Istmo, 1973, p. 147-166.

2 "Fiesta y alimentación en la España moderna: el banquete como imagen festiva de abundancia y refinamiento" en Espacio, tiempo y forma, Revista de la Facultad de Geografia e Historia, Historia Moderna, UNED, serie IV, 10, Madrid, 1997, ps. 53-98.

${ }^{3}$ Estilo de servir a Principes, con exemplos morales para servir a Dios. Por Don Miguel Yelgo de Bazquez Natural de Loxa. Dirigido al Excelentissimo señor Duque de Vzeda. Con privilegio. En Madrid, por Cosme Delgado, Año MDCXIII.
} 
tema. Y el hecho de ser publicado implica que fue propuesto como ejemplo a imitar, aunque después pudiera aplicarse de manera parcial o adaptada a las circunstancias concretas de cada casa.

Resulta evidente que el modelo del Estilo de servir a Principes de Yelgo de Bazquez era la organización de la Corte de los Austrias españoles, aunque el libro tratara de simplificar algunos aspectos, pues por grande que fuera la casa nobiliaria, independientemente de su riqueza y de su poder, lo correcto era que estuviera por debajo de la Casa del Rey, que en esto, como en todo lo demás, ocupaba el vértice de la pirámide social. Además, difícilmente podía una casa nobiliaria, aunque quisiera, mantener el nivel de lujo de la Corte real, con la cantidad de recursos humanos y económicos que suponía.

El servicio de una gran casa tenía una función educativa y formativa. Servir a un gran señor era un modo de aprender modales y buenas maneras, que serían después muy útiles para desempeñar mayores encargos. Además el servicio doméstico de la casa, siempre que fuese fiel, honrado, eficaz y diligente en el cumplimiento de sus deberes, era un modo muy práctico y directo de asegurarse la protección del señor al que se servía, de manera que pudiera tenerle en cuenta para otros encargos de mayor envergadura al servicio de la casa y recomendarle a otros señores o incluso al propio monarca. Por esos motivos muchas familias trataban de colocar a sus hijos como pajes de grandes señores. El carácter educativo del servicio en las principales casas nobiliarias estaba muy claro ya desde la baja edad media y se recogía en múltiples obras. Por ejemplo, el primer recetario cortesano español de la época moderna, el Libre del Coch del Mestre Robert, comienza haciendo alusión a esta finalidad formativa de los jóvenes: "Com sie molt necessària als jovens de tendre edat apendre de les virtuts la carrera, e majorment aquells qui en delliberació de servir als hòmens de major grau o condició se deliten..." Y continua explicando las obligaciones de los principales servidores del señort.

Yelgo confiaba al maestresala la función de maestro educador de los jóvenes pajes, a los que comparaba con los novicios de un monasterio, pues más que enseñarles específicamente a servir la mesa y otras tareas domésticas, a hablar bien y a moverse con elegancia, debía enseñarles a ser personas, buenas personas. El maestresala tenía, pues, el deber de dar ejemplo:

"y es el maestro de los pages: porque se ha de remirar en enseñalles las cosas de virtud, y el modo que han de tener para servir a su amo, hasta el modo de habjar a la usança de palacio y los lenguages corteses, y linados:

\footnotetext{
${ }^{4}$ Mestre Robert: Libre del Coch, Barcelona, Curial, [982, ps. 23-37.
} 
finalmente ha de entender, que es maestro de novicios, y que les ha de enseñar virtud, y a servir, porque los pages son sus discipulos, y ansi, si el page que no supiere servir no le echaran toda la culpa: porque la mayor parte tiene el maestro de un noviciado de un Monasterio, para que sus discipulos salgan tales, el ha de andar siempre a la mira, y haziendo el primero todo lo que han de aprender los discipulos: por que mal puede aprender un novicio, sino lo vee al maestro obrar primero. (...) Finalmente hasta el comer, porque en la Religion, comen con Dios, y aca en el siglo suelen aver hombres, que con su malicia comen con el pecado. Y para que comays con Dios, señor Maestresala, y coman vuestros discipulos, es menester que andeys con mucho cuydado, como lo anda el santo religioso, que si vos no andays a la mira, mal podreis ver de quien cogea cada uno para ver el que no es para casa, que el maestro tiene de costumbre andar celando sus discipulos, (...) porque alli se suele de echar de ver el que es para Frayle uno, y aun muchas vezes tomandole el boto para la profession, dezir: Fulano no es para Frayle, y dessa manera lo ha de hazer el Maestresala, que ha de andar a la mira, y en haziendo alguno alguna cosa, que no parezca bien, sea contra el servicio de Dios, que sea contra el servico de su amo, reñir, y no bastando el reñir, aconsejar al señor, diziendo, que fulano no es para casa, ò este page."s

Dentro de las responsabilidades del maestresala, como educador de los pajes, estaba también la obligación de corregirles y reprenderles cuando no se comportaban adecuadamente. Yelgo de Bázquez advertía que debía hacerlo de manera justa y proporcionada a su falta, sin ser excesivamente blando, pero sin caer tampoco en rigores exagerados:

"El Maestresala tiene obligacion a estar en casa, quando el señor va a fuera, para ver el page que haze falta para reñirle y executar el castigo, porque es tambien su alguazil, y no ay cn la casa aquien ellos tanto teman, como a el, $y$ en haziendo porque, es necessario el hazer justicia, para que no passen adelante sus desverguenzas, y como buen alguazil, (...) Assi digo señor Maestresala que nadie viene a servir a otro de puro rico, fino de puro pobre, que si algun page hiciere alguna cosa, que no sea de malicia, sino de saber mas, que no seays Alguazil vengativo, aunque esteys disgustado, sea por lo que fuere, ni deseys que hierre, para confesar que lo despidan, que es pobre, y se vino a valer desta casa para valer mas, y no menos, y en los pechos nobles no ha de aver rencor ninguno, que no aya pesadumbre que no passe por alto." ${ }^{\prime 6}$

'Yelgo, 33v-35r.

"Yelgo, 40r-42r. 
Muy característico de la época era el afán moralizante de la obra de Yelgo de Bazquez, en que se trataba no sólo de servir a un gran señor, sino de servir al más grande de todos los señores, Dios mismo, estableciendo una curiosa manera de obtener la salvación eterna, mediante el perfecto cumplimiento de los deberes y funciones de todos y cada uno de los criados en el trabajo de la casa. En la mentalidad de la época, servir a un gran señor, si se hacía bien, equivalía a servir a Dios y los méritos que se hacían en este mundo se podían aplicar a conseguir alcanzar el otro mundo.

El servicio de una gran casa nobiliaria era muy numeroso y se hallaba perfectamente jerarquizado. Cuanto más noble, rica y poderosa fuese una familia, mayor era el grado de especialización de los criados que componían el servicio doméstico. En el Estilo de servir a Príncipes, Yelgo de Bázquez explica detalladamente las obligaciones de todos y cada uno de los criados de una gran casa nobiliaria. A partir de las funciones de los servidores relacionados con la cocina o con el servicio de la mesa se puede reconstruir la organización de la mayoría de los aspectos relacionados con la alimentación de una gran casa noble.

La cúspide de la pirámide del servicio doméstico la ocupaba el Mayordomo, que tenía la responsabilidad del conjunto de la casa y de todo el personal del servicio. Debía supervisarlo y vigilarlo todo, para asegurar el orden y la armonía. De la experiencia del Mayordomo dependía en gran medida la buena marcha de la vida doméstica: "no ay cosa de que el señor tanto guste, como saber que tiene un Mayordomo, que le trae contenta la casa".

Entre las múltiples obligaciones del mayordomo destacaba el control de todas las cuestiones relacionadas con la alimentación. Como todo el trabajo no podía hacerlo solo debía buscar colaboradores de confianza, que desempeñaran bien sus tareas y lo hicieran con un gasto razonable:

"Ha de procurar buenos oficiales, pues aviendolos ruynes, no puede bastar su cuydado, para que se coma regaladamente, y se sirva la mesa con la limpieza que es razon, y para que lo que se gastare sea con concierto, y razon, y los que fueren buenos procurar de conservalios, y los que no tuvieren las partes que conviene, echallos..."

Por debajo del mayordomo existía una compleja y jerarquizada organización de servidores, que recibían diversos nombres, según su categoria y su función dentro de la casa:

\footnotetext{
${ }^{7}$ Yelgo, $3 \mathrm{v}$

"Yelgo, 4r.
} 
"En casa de un Grande no les llaman a los pages criados, sino pages: porque criados son los oficiales de la casa, como diximos hablando con el mayordomo, aunque verdaderamente todos los que comen pan del señor los llamo yo criados, pero de dentro de la casa no lo son, hasta que el señor les haze oficiales della, y les liaman criados, como es mayordomo, camarero, secretario, Tesorero, contador, gentileshombres, que en siendo gentilhombre, aunque no tenga oficio le llaman criado, y los pages, ni lacayos, ni despensero, ni botiller, ni guardaropa, ni moço de camara, ni cocinero no se llaman en la casa del señor, sino a cada uno por su oficio, y fuera todos dize que son criados."

Cuestión previa, pero muy importante era la organización del servicio de boca y la compra, sobre lo que se había de ejercer el máximo control y vigilancia. Misión muy importante del mayordomo era vigilar los gastos de la casa y cuidar todas las propiedades y provisiones existentes. El control obedecía tanto a la necesidad de mantener un buen servicio, sustituyendo los utensilios que se estropearan o deterioraran, como a la necesidad de evitar robos y sustracciones, especialmente si se trataba de objetos de gran precio, como los servicios de plata. Especial cuidado se recomendaba con respecto a la botillería, es decir el vino, pues en las casas de categoría se consumían vinos de calidad, muy caros, y era muy importante que no se perdieran botellas o se consumieran indebidamente. También la cera, para iluminar, y la leña y el carbón, para cocinar y para calentar la casa en invierno, habían de estar bajo estricto control:

"Los partidos que se pagan por la despensa no los concertara ningun Veedor, sin dar cuenta al Mayordomo, y en lo que toca alterar lo que se acostumbra dar en la casa, no lo hara sin consultarlo con el señor.

Ha de tener cuenta de hazer tanteo de quatro en quatro meses con los reposteros de plata, y ropa blanca assi para ver lo que les falta, como si esta bien tratado, y si hallare que falta algo, dara cuenta dello luego al Contador, para que haga fenecimiento, y lo pague: reprehendera si no lo tuviere con limpieça, y de manera que no reciba daño, y para esto sera bien que tenga una relacion del cargo de plata, y ropa blanca.

Con la botilleria se ha de tener gran cuenta, que es el principal desaguadero de una casa, y que entre y salga con mucha cuenta y razon lo que huviere en ella, y si huviere algo de por junto este a parte, y debaxo de llave, y no se de al botiller, y si no que lo huviere menester para el gasto de cada dia.

En lo que toca a la cera, se ha de poner debaxo de llave, y ha de aver un libro a parte de la cuenta de todo lo que se comprare, en que diga las

"Yelgo, 35r-35v. 
hachas, y velas que fueren (...) la leña a de estar debaxo de llave, y asi mismo el carbon, y manojos, para que se pueda tener cuenta de que no se gaste, sino lo que no se pudiere escusar, en lo qual coviene que aya mucho recaudo."1"

El control periódico, cada cuatro meses, de las reservas de alimentos, bebidas y utensilios servía para evitar fraudes, descuidos y despilfarros. En caso de faltar algo o haberse estropeado se pedían responsabilidades a los encargados, que debían sufragar por su cuenta las pérdidas experimentadas:

"El botiller no ha de dar ninguna cosa sin orden del Mayordomo. A todos los oficiales de botilleria despensa, y tinelo, y cocina, se les ha de encargar todas las cosas, que a cada uno se les entregare para el servicio de su oficio, y tomalles cuenta de quatro a quatro meses, par entender lo que faltare, y comprarse ha a costa del oficial a cuyo cargo estuviere, y de todas estas se ha de dar memoria en la Contaduria, y despues lo que mas se fuere comprando, para que en ella aya la razon de lo uno y lo otro."1

La organización de la alimentación no podía improvisarse. La previsión era cualidad imprescindible del mayordomo. Era muy importante organizar las comidas con tiempo, para disponer todo lo necesario adecuadamente, mucho más si habian invitados. La costumbre habitual era que cada noche el mayordomo y el veedor se reunieran para decidir el menú de la comida y la cena del día siguiente, los productos que se debían comprar para entregar al cocinero y las cantidades, en función del número de comensales:

"Para ordenar la comida, y cena del dia siguiente, se han de juntar el Mayordomo, y el Veedor cada noche, y ordenar conforme al tiempo, y a lo que huviere, y se pudiere aver, lo que se ha de adereçar, y servir, de mane$\mathrm{ra}$, que sean cosas buenas, y bien sazonadas, $\mathrm{y}$ aviendo huespedes, $\mathrm{y}$ personas de cumplimiento, conforme a la ocasion, se acrecentara lo que le pareciere, lo cual se ha de hazer con mas cuydado, y con el mismo mandar que todo sea muy bien sazonado, tiniendo mucha cuenta, y de que todo se entregue al cocinero con cuenta y razon.",12

Asegurar el aprovisionamiento de la casa era una cuestión muy importante. Muchos productos alimenticios procedían de las fincas de la casa, algunos eran regalos, pero la mayoría eran comprados en el mercado. Las compras no podían ser improvisadas, se habían de organizar mediante el acuerdo del mayordomo con un veedor. Para mayor claridad se debía hacer por escrito una lista de la compra.

\footnotetext{
in Yelgo, 9v-10v.

${ }^{11}$ Yelgo, 11r-11v

12 Yelgo, 4r-4v.
} 
Según los productos, unas compras se hacían en grandes cantidades y se mantenían los productos en reserva en la despensa o en la bodega, pero la mayoría de los alimentos se compraban diariamente. Todo debía ser controlado y sólo alguna cosa de poca importancia podía comprarla el despensero sin el permiso previo del veedor. Los productos habian de ser de buena calidad y había que tratar de conseguirlos al mejor precio posible. Yelgo aconsejaba que los encargados, el mayordomo y el veedor, estuvieran informados sobre los precios del mercado, para evitar engaños. Una vez realizada la compra, el despensero estaba obligado diariamente a llevar las cuentas en borrador:

"Para las compras se ha de juntar el Mayordomo, y un veedor, para ordenar lo que se huviere de comprar y el veedor se ha de hallar siempre presente a las compras que se hizieren y hazer, que lo que se comprare sea bueno, y en el mejor precio que sca posible, y lo ha de señalar en el borrador del despensero, y a las noches se han de juntar para escrivir el orden que estuviere mandado, y el despensero no ha de comprar cosa ninguna, sin que el veedor este presente, si no fuere una cosa menuda, por pura necessidad de no poderle hazer otra cosa, $y$ ha de procurar saber sin que se entienda, los precios que corren en la plaça, para que no hagan ningun fraude." $" 13$

En las compras tenía responsabilidad principal el Veedor, que era el encargado del control de cantidades, calidades y precios de todos los alimentos adquiridos y además debía vigilar a los demás criados de la casa que tenían relación con las diversas fases del proceso de la alimentación, el comprador, el cocinero, el botiller. Yelgo de Bázquez le dedica a este oficio todo un capítulo del libro: "Capítulo XVII: Del modo de servir del Veedor, y sus obligaciones". Una de sus principales características había de ser la honradez, de tal manera que no sólo fuera honrado él mismo, sino que vigilara para que lo fueran también los otros servidores, especialmente el comprador y el cocinero:

"El Veedor es tiniente del Mayordomo, llamase Veedor, porque ha de dar fe de todo lo que el comprador compra, y lo que se le entrega al botiller, y veer como se despende el recaudo que se le entrega al cocinero, teniendo grandissimo cuydado, de que no hunda lo que le dan para que guise: porque como dixe hablando, con el mayordomo, haziendose el cocinero, y el Vecdor a una, el tercio se pierde al señor, por esso deve de ser, el Veedor, hombre de bien, que si no lo es, mucho se le perdera al scñor, haziendose en la plaça con el comprador, y en casa con el cocinero, miren que dos tratos estos, para que dexe el señor de ser robado: y en haziendo esto, aunque el señor tenga un millon de renta, no tendra un real, que mien-

${ }^{13}$ Yelgo, $11 \mathrm{v}$ 
tras mas tuviere mas le hurtaran, y aqui suele ser culpa del mayordomo, que suelen ser tan blandos, que suelen consentir algunas destas desordenes, lo qual hazen mal, sino echarlos de casa en haziendo tantico, que quien haze un cesto, hara ciento, que esto del hurtar es cosa golosa, y en empeçando solo Dios lo puede remediar, porque es un vicio, que el que le sigue, no lo dexa, sino es con el pellejo."14

E1 veedor debía ser además diligente y cuidadoso, enterado de los precios de los diversos alimentos, pues si era perezoso todos podían aprovecharse de su falta de vigilancia, para hacer su negocio a costa de los intereses del señor:

“... y esto ha de ser sin apartarse un punto del comprador, viendo a como cuesta la perdiz, a como la gallina, quanto el capon, en fin mirar a como paga lo que lleva para el gasto del señor, porque si no teneys cuenta, la mitad de lo que costare cada cosa, o eschara de mas, y no seays perezoso, sino seguid siempre al comprador, que es vuestro oficio: y si por vuestro descuydo hurta (el comprador), y echa de mas en lo que compra, vos lo aveys de pagar, y teneys obligacion de restiuyrlo, que por pereza de los Veedores suelen enriquezer los compradores con la hazienda del señor, como yo he conocido Veedor tan perezoso, o tan gravedoso, que amaneciendo se levantava con el comprador para yr a comprar, y en saliendo de casa dezia al comprador: Yd vos a comprar, y comprad lo mas barato, que pudieredes que en tal parte os aguardo. El comprador via el cielo avierto, porque le abrian la puerta para que hurtase, porque mayor gusto puede recibir el ladron, que quando hurte, no aya quien lo vea..."."s

Debía estar el veedor siempre pendiente de sus obligaciones, sin ceder a distracciones que le pudieran apartar del servicio a su amo, por eso Yelgo de Bázquez desaconsejaba a los mujeriegos, que se entretenían con sus amoríos, en lugar de vigilar la compra:

"Otro Vcedor conoci muy mugeriego, y no tenia lugar de yr a holgarse, sino era dexando al comprador, que comprasse como quisiesse, y que quando huviesse comprado, viniesse por casa de sus amores, y le llamasse, porque entrassen en casa ambos juntos, por amor del mayordomo: y le advertia, que si preguntasse el mayordomo, si avia ydo a comprar con el, dixesse, que si, y assentada por memoria todo lo que avia comprado el comprador, para dar fe dello al mayordomo." ${ }^{\text {"16 }}$

\footnotetext{
14 Yelgo, 132r-133r.

15 Yelgo, 133v-134r.

I" Yelgo, 134v-135r.
} 
Sobre la fidelidad de los veedores Yelgo de Bázquez insiste muchísimo, pues considera que su responsabilidad personal es muy grande y que de él depende, en gran medida, el buen comportamiento de otros criados y la buena administración de la casa, evitando fraudes y abusos de todas clases:

"Y por estas cosas deve el mayordomo advertir, que el Veedor sea hombre sin vicio, porque en teniendolo, todo andara malo, que hurtando, o dando ocasion para hurtar. Ha de ser hombre assentado, que este sin salir de casa toda la semana entera, sino fuere quando sale a comprar con el comprador, que en casa de los Mercedes llaman despenseros, que entonces es fuerça ha de seguirlo hasta bolver a casa, y no fiarse del, como tengo dicho, porque ay comprador, que no sea codiciosos, que assi le sucedio mal a Judas, y es propio del despensero, y comprador, procurar engañar al Veedor y al mayordomo, y a su señor di llegare a quentas, contando por lo que vale dos quatro. De los venteros no digo nada, porque sera nunca acabar, que ya es notorio, que un ladron no se pone en un camino, sino es para hurtar sin que nadic lo vea, porque dizen que venden gato por liebre y esto basta para lo que es venteros."'?

Además de vigilar la compra, el veedor había de supervisar la correcta utilización de las reservas alimenticias, cuidando se diera puntual información al escribano de raciones de todo lo que se gastaba y entregando al cocinero los productos en la cantidad necesaria, sin hacer trampas ni engaños. Entre los productos que cita figuran los endulzantes, la miel y el azúcar, de los que acostumbraba a haber una cierta cantidad permanente en la despensa para los diversos usos de la cocina, pero que eran entonces, sobre todo el azúcar, productos caros y muy tentadores, que debían ser muy vigilados:

"El Veedor tiene obligacion de dar quenta al escrivano de raciones de todo lo que se gasta con buena fe, y con mucha verdad, dandole por peso y medida al cocinero todo el recado, como es miel, y açucar, $y$ otras cosas para guisar la comida, que en esto del pesso y medida, ay muchas bellaquerias." $" 18$

Otro producto que el veedor había de comprar con frecuencia y en cantidades importantes era el vino, procurando tener algunas reservas, sobre todo en las casas ricas que podían disponer de buenas bodegas y comprar buenos vinos, pues sólo los vinos de la mejor calidad podían conservarse con unas ciertas garantías, ya que los vinos normales podían avinagrarse y estropearse con bastante facilidad. Si fácil era para un veedor poco honrado engañar en la compra diaria, más

\footnotetext{
${ }^{17}$ Yelgo, $135 r-135 v$.

${ }^{18}$ Yelgo, 135v-136r.
} 
fácil y más rentable podría resultarle hacer trampas con los productos que se compraban regularmente y en cantidades de una cierta consideración. Yelgo de Bázquez hacía unas cuantas advertencias sobre la compra del vino, pues consideraba que era un producto con el cual se podían cometer muchos abusos, en las cantidades, en las calidades y en los precios. Ponía sobre todo en guardia contra las trampas de los taberneros, que en la época solían tener muy mala fama:

"... y yo he conocido fieles tan falsos, que, porque el tavernero le regalava con el buen vino, le conssentia que hurtase, de manera, que en Sierramorena no se podia hurtar mas a boca arrancada. Porque el tavernero tenia medidas para de noche, y medidas para de dia, las de dia eran, que tenian un poquito menos, que estavan mas raspadas de lo que era menester: las de la noche eran en demasia, porque tenian todas las medidas un agujerito en el suelo, y quando median vaciavan de espacio, porque saliesse mas vino, y quando venia el fiel consentidor, que yo conozco fieles tan honrados, y tan santos, que jamas se les ha entendido, ni sospechado que ayan consentido cosa mal hecha, como este que yo conoci en cierta ciudad destos Reynos, que llamo aqui consentidor, que como digo, viendolo, no se le dava nada. Pero quando entrava otro, o algun alguazil, entendiendole venir por la calle, que es siempre a las puertas de las tavernas tienen una centinela que divisa, y en avisando, tapan los agujeritos con unas pelotitas de cera, que tienen hechas para el efecto, y este agujerico suele estar mas de ordinario en la medida de a quatro de noche, que se quartea a menudo, esto, y echar a quatro arrovas de vino una de agua muchos ay que lo han echo, por causa de algun fiel, que no lo a hecho castigar por la primera: (...) harta lastima es, que por vuestra ocasion le hurten al pobre trabajador, harto de cavar, y segar, de dos quartos de vino le traen uno, que le quitais vos con vuestras bellaquerias, lo que Dios le da por su trabajo."'"

Otra de las advertencias se refería a los vendedores de aceite, pues como en el caso del vino también eran posibles muchas trampas:

"Y el tratante en azeyte, porque os embio un poco, diziendo, que tiene tarto desseo de serviros, y que recibays este azeyte, pues sabed, que antes se lo diera a un Moro, sino que le es fuerça el enseñaros buena cara, porque le consistais sus bellaquerias. No lo hagays, Fiel: y responde: Pardiez comer tengo, sustentemen yo y mi casa, y hurte el que quisiere. A desdichado de vos, digo yo, que por sustentar vuestra casa, y sustentar vuestro cuerpo, quereys dessustanciar lo mejor, y mas preciado que teneys, que ha de durar para siempre, mientras Dios fuere Dios, que is vuestra alma..."20

"Yelgo, 136r-137r.

${ }^{20}$ Yelgo, 137r-137v. 
El otro gran capítulo del servicio de la alimentación correspondía a la cocina y el cocinero. Especial vigilancia debía tener el Veedor sobre el cocinero, pues, en opinión de Yelgo de Bázquez los cocineros eran muy inclinados a defraudar a sus señores, reservándose para sí parte de los productos que le habían sido entregados para cocinar:

"El Veedor ha de estar con mucho cuydado, mirando lo que se gasta de recaudo en cada plato, y de manera que no le engañe el cocinero, porque si se descuyda tantico la ha de mamar el Veedor, porque los cocineros en esto de arañar son muy diestros que raposos, y es menester vivir con cuydado, porque en faltando, quando llegue la hora del comer, tendra la mitad apartado, como dize Guzman de Alfarache ${ }^{21}$, y mirar que si un plato se puede aderezar con media libra de açucar, que no lleve el cocinero una, y si es menester un quarteron de miel, no le de una libra, entendiendose, que todos los aderezos que fueren menester para los platos del genero que fuere no le de al cocinero mas del tercio de lo que pidiere, que por estas demasias se ordeno un veedor, lo mirasse, $y$ viesse lo que se gastaba por sus ojos, porque el mayordomo no podia acudir a estas en la cocina, y despensa, y botilleria..." ${ }^{.22}$

Por otra parte, sin aflojar nunca la vigilancia, era también preciso que existiese acuerdo entre el veedor y el cocinero, pues sólo si se hallaban en buenas relaciones podía marchar bien el servicio. El cuidado debía ser mayor cuando en lugar de una comida ordinaria se trataba de un banquete, pues en medio de la confusión era fácil hacer desaparecer no sólo algunos productos, sino una parte del contenido de un plato o incluso platos enteros. En el trayecto de la despensa a la cocina y de la cocina a la mesa eran tantas las manos y las bocas que no era raro que muchos alimentos se perdieran:

"El Veedor tiene cuydado de ordenar la comida, y para que no se rian de los oficiales de la casa, es menester que lo sepa hazer con mucho concierto, de manera, que si el señor quisiesse hazer una comida de doscientos platos, los ordene liberalmente, y con tanta destreza, que no ayais menester al cocinero: que yo confiesso, que por habil que sea el Veedor, para esto ha de menester al cocinero, y ordenandole, pondra por memoria todos los platos, porque de no sentarlos, se suelen perder algunos, o quedarse en la cocina, o de la cocina a la mesa, que en tales ocasiones no ay criado que no procure regalar con lo mejor a quien bien quiere, y tiene

\footnotetext{
"La famosa obra de Mateo Alemán, Guzmán de Alfarache. Atalaya de la vida humana, publicada en Madrid en 1599, ofrece interesante información sobre la alimentación -y el hambre- en general y en concreto sobre la picaresca en torno a las cocinas de los grandes ser̃ores. Vid especialmente la parte primera, libro Il, capítulo V "Cómo Guzmán de Aifarache sirvió a un cocinero" y capítulo VI Guzmán de Alfarache prosigue lo que le pasó con su amo el cocinero, hasta salir despedido dél."

${ }^{22}$ Yelgo, 133v-133v.
} 
obligacion: y asi deve abrir los ojos el Veedor, y aun plegue a Dios que baste para que no los hurten, y donde tienen mas peligro, es al tiempo de sentarlos en la mesa, que alli se desaparece el page, haziendo espaldas el gentilhombre, y a este tiempo se ha de poner el Veedor detras de la mesa, apartadico un poco, con la memoria debaxo de la capa, y como se fueren sentando, el Veedor echando una raya secretamente, sin que sea echado de ver, porque sino lo hace assi, lo mejor se perdera: y si a este tiempo huviere platos menos, diraselo al mayordomo..."

El cocinero era un factor fundamental. Si se quería asegurar una alimentación de calidad, tal como correspondía a la categoría de un gran señor, era imprescindible contar con un buen cocinero. Yelgo de Bázquez dedicaba a la figura del cocinero todo el Capítulo XVIII, "Del modo de servir del Cocinero, y sus obligaciones". Del cocinero dependía una parte muy notable en el empeño de satisfacer el gusto y el placer del amo, por tanto era un miembro importante del servicio de una casa, aunque no fuese uno de los servidores principales y su ámbito de acción se redujera a la cocina. Un cocinero que amase su oficio era considerado como un gran hallazgo, que debía ser muy considerado, mostrándole el aprecio con un buen trato y buenas palabras. El señor debía procurar conservarlo en la casa, pues siempre era mejor tener en el servicio personas conocidas que ir cambiando a cada momento:

"Yo estoy bien con el Cocinero, quando es buen oficial, y el señor lo deve estar, pues de quien cuelga el regalo del sustento del suyo, y assi el Cocinero que guisa a gusto, y regalado, se a de estimar, ya que no se le satisfaga con dinero, satisfagase con buenas palabras, y amorosas, dichas de manera, que entienda que le quieren bien, y asi con el, como con todos los criados, que en tiniendo un criado a gusto, estimarle como a criado honrado. Hame parecido favoreser aqui al Cocinero, por merecerlo, y ser hombres tan humildes, que en la casa no hablan, sino en su cocina, y no se meten en otras pretensiones, sino pretendiendo ser siempre el mejor maestro para dar gusto a su amo, que desta manera viene a valer, y a ser estimado de cualquier señor, y para esso sirven, para que los honren. $Y$ asi el mayordomo le ha de dar siempre buenas palabras, ya que no pueden hazer mercedes, y esso mismo han de hazer. Los que goviernan, que no pudiendo hazerlas, lleven buenas palabras, y buen despidiente, y vayan contentos, como dixe en el capítulo primero, que aunque no livando lo que pretenden, no lo yran del todo. El Cocinero no pretende otra cosa, sino acertar a dar gusto a su amo, y con saber que le quiere bien el señor, y que el mayordomo es su amigo, esta contento, y se estara toda la vida en casa. Que en verdad, que si a un criado le parece mal el andar de casa en casa, que al señor le parece peor no saber conservar un criado que dessea el gusto de su amo, porque el dia de oy se hallan pocos: porque ay muchos, que por la menor palabra que el mayordomo les habla, buscan otra casa, que no tienen ver- 
guença de yr a conocer voluntades nuevas, que hazerlo assi, no es cosa de hombres de bien, que quien no sabe sufrir, en picaro viene a dar..." ${ }^{\prime 3}$

Condición fundamental, siempre repetida en todos los tratados y recetarios que se ocupaban de un modo u otro del tema alimentario, era la limpieza y el orden que debían reinar siempre en la cocina. El cocinero debía ser extremadamente limpio y además dar ejemplo y exigir que sus ayudantes y pinches también lo fueran, lavándose con frecuencia las manos y teniendo siempre cuidado de hacer todas las tareas con gran pulcritud:

"... y lo que guisare sea con mucha limpieça, y enseñarsela a tener a los galopines de la cocina, y no consentir que ninguno llegue con las manos a lo que esta guisado, porque aunque es verdad, que como ayudan, no pueden dexar de llegar: pero entiendese para pelar, o cortar, o tener, o asar, o perdigar, pero despues de asado, o guisado, echarlos fuera, que no lo vean de sus ojos, y mas si es asqueroso, que no se lava las manos, si no quando friega las ollas, y los de mas aderezos, y aun entonces no se las lava, si no se las dexa llenas de grasa: porque dizen ellos, que el que anda mas sucio, esse es el mejor moço de cocina: y assi sera bien, que el cocinero los eche afuera..."24

Además, el cocinero debía estar siempre atento a que los pícaros de cocina no gastaran alguna pesada broma, como la que Yelgo de Bázquez explica a modo de ejemplo de las porquerías que a veces se llegaban a hacer en la cocina con las comidas y las bebidas. Unas veces porque eran simplemente jóvenes y con ganas de divertirse, otras con verdadera mala intención. El submundo de las grandes cocinas, siempre muy atractivo porque era un buen medio de acercarse al alimento y poder acallar el hambre, era un foco de bromas, desórdenes, hurtos, trampas y hasta violencias, como explican desde la documentación del palacio real, que recoge verdaderas peleas entre bandos de galopines, hasta la novela picaresca, como el Guzmán de Alfarache, que narra las aventuras y desventuras de algunos de estos atrevidos e insolentes pinches. La anécdota de Yelgo de Bázquez resulta digna de figurar en alguna de aquellas novelas de pícaros tan célebres en la época, pues con frecuencia la realidad, caso de serlo ésta, supera la ficción:

“... y a cerca de sus groserias contare esta. Que tieniendo el cocinero del Conde de Miranda un moço de cocina, que se preciava de gran picaro, y el cocinero era muy amigo de jugar a las cargadas un açumbre de vino, $y$ aun pienso que se jugavan treinta, este galopin era muy diligente, $y$ todas

${ }^{23}$ Yelgo, 140v-142r.

${ }^{24}$ Yelgo, $145 \mathrm{r}-145 \mathrm{v}$. 
las vezes que lo embiavan por vino, por sisar un quarto, lo orinava en el jarro, y algunos de los que enbiava dezian: Ven aca galopin, de donde trays ese vino que sabe a sal? respondia el galopin, de donde suelo, si no que dizen, que es muy añejo, y que el rancio le da esse sabor, que ya lo pregunte yo en la taberna, y ellos callaron, y bevieron su vino, mire el cocinero que ay que fiar en ellos cada cosa que sea de limpieça, porque no puede tener cosa peor que no ser zeloso de la limpieça.".3.

Para el buen servicio de la casa convenía que el cocinero fuese lo que en la a de denominaba "liberal", es decir, expeditivo, diligente y resuelto a la hora abajar, de tal manera que afrontara y solucionara la tarea de cocinar con presy eficacia, pues de lo contrario los demás servidores se resentirian de su falta iligencia y rapidez: "Ha de ser el cocinero muy liberal, que lo que tomare a manos, tan presto como lo tome sea adereçado, no ser flematico, porque ira al Veedor, y nuayordomo."26

La fidelidad, exigible a todos los servidores, era igualmente imprescindible ; 1 cocinero. Fidelidad en el sentido de honradez, de manera que cuando le $\mathrm{n}$ un pastel de carnero, que era entonces una carne apreciada y cara, no lo sra de vaca, más barata, para quedarse la diferencia del coste. $Y$ lo mismo con :onservas en dulce, que no las haga con miel, más barata, en vez de con azúmás cara, rebajando la calidad de la confitura con el mismo obvio propósito btener un beneficio particular a costa del señor. Fraudes que según Yelgo de quez eran frecuentes en la época entre los bodegoneros y confiteros:

"Ha de ser el cocinero fiel, que quando le mandaren hazer un pastel de camero, no lo hagan de vaca, y llegando aqui dexolo para los pasteleros, que les toca mas que al cocinero, y para los vodegoneros, que tienen tan poca fidelidad, que si les piden una tajada de carnero se la da de oveja, que y o se las he visto comprar entre Vaciamadrid, y Vallecas, y meterlas de noche en sus casas, que aunque aya quien lo vea, con un carnero que se reparta, se calla las ovejas. Ellos dizen, que estando manida, que es mejor que el carnero, plegue a Dios que no salga el lobo del infierno en busca desta oveja, y le pese a quien la tuviere. Quando le mandan hazer conservas, echar todo el azucar fielmente, sin echarle miel, por hurtar azucar, y esto dexarlo para algunos miseros confiteros, que quando hazen las conservas, que le es fuerça para yr buenas, que lleven sola azucar, y por ahorrar algo, echan lo medio de miel, y si no es lo medio, sera algo, no ay ya de quien fiar, en lo dulze, y en lo agrio, y aun en lo que no es de comer. El 
mundo ya esta estragado, y assi digo al Cocinero que sea fiel, y no hurte, guardando, y sabiendolo que le emos dicho en su oficio."'z

La cocina era el centro de elaboración y de preparación de los alimentos y requería, por tanto, un cuidado especial y disponer de espacios convenientes y adecuados a las funciones que debían realizarse, así como los muebles y utensilios necesarios para poder cocinar de la manera correspondiente a los elaborados y complicados platos que se estilaban. Evidentemente existía entonces como siempre una estrecha relación de mutua dependencia entre espacios y utensilios disponibles y nivel de sistema alimentario y si se esperaba un alto nivel culinario había, consecuentemente, que dotar al cocinero de una cocina y de unos instrumentos idóneos. Mientras las clases populares pasaban con un sencillo hogar y algún fogón como lugar para cocinar y unos cuantos utensilios básicos, ollas, cazuelas, sartenes, en una cocina de una casa noble la dotación debía ser mucho más completa y variada. La obra de Yelgo de Bázquez ofrece un panorama expresivo de las condiciones materiales que debía reunir la cocina de un gran señor:

"Tiene obligacion el cocinero, para que lo que guisar salga con sazon pedir al mayordomo toda la herramienta, y aderços necessarios para la cozina, pidiendo: Lo primero, una lampara que este en medio de la cozina para de noche, tener una alazena para guardar recaudos, para lo que fuere menester. Tener junto de la cocina un aposento donde duerman los galopines de la cocina, porque quedandose a dormir dentro, suelen hazer algunas suciedades. Ha de tener cuydado que los que recibieren sean desbarvados, gente moça, porque barvados siempre andan con las barvas en el manjar blanco, o en lo que ayudan a guisar, que con la mucha limpieza siempre se estan pelando. Tener un vasar donde tenga las ollas limpias. Tener una banca lissa y ancha para tener la massa. Tres morteros unos mas grandes que otros, para lo poco, y para lo mucho. Quatro bancos clavados a modo de tajoncillos para picar la carne, tener un horno para las cosas que se han de coçer en el, dentro de la cocina un poço y una pila junto a el, y una vacia de madera para echar en agua el pescado, y otras dos vacias grandes de cobre para lavar las cames, y un candelero alto de pie, que se pueda passar de una parte a otra, tener un pinzel para adovar los pasteles, tener otro aposento junto a la cocina, donde este la muela para afilar los cuchillos, y tener cestas, y otros trastos en el, y cedizos con que cerner la harina, y cediços con que cerner azucar, y cerner las especias, tener caçuelas altas y baxas, y orteras para las tortas, calderas ovadas, y coberteras para ellas para cocer pescados, estufas para estufar, sartenes ovadas para freyr, para escaveches, tener seys o siete calderas, unas mas chicas que otras, tener un caldero, que quepa quatro cargas de agua para calentarla, tener una docena de caços chicos y grandes, media docena de alnases para hazer cosas

${ }^{27}$ Yelgo, 155v-156v. 
diferentes fuera de la cocina, sin echar la lumbre en el suelo, tener dos costales de cuero donde este la harina, botes para especias, rodillo para el horno, y barredor, dos tinajas para tener agua, si no huviere poço, fucre dentro de la cocina, tener un peso, donde pese el recaudo, que ha de llevar lo que se guisa, tener cuchillos para rasgar, cuchillos para picar, cuchillos para cortar, cuchillos para hazer quartos, carnero, o ternera, o venado, yerros para bolver tripas, y limpiaollas, tener assadores chiquitos para paxaricos, tener yerros para macarrones, jeringa para hazer frutas, tenedores, para cortar assados y cocidos, una carretilla para cortar massa, tener dos pares de parrillas grandes, y chicas, asadores dobles, y sencillos, y de torno, una paleta para sacar lumbre, una docena de cucharas para espumar chicas, y grandes, tener moldes para hazer obleas, un par de fuelles pae queños para encender la lumbre, tener unas caxetas, donde tener aceyte, : vinagre, y aguas de olores para dar olor a las tortas, pasteles y empanadas, tener una pala honda de madera en que sacar la basura quando barran la cocina, tener en la cocina antes de entrar dentro, una reja de palo para que se pueda dar, y tomar lo que se ofreciere, sin entrar dentro a estorvar."28

Naturalmente no bastaba con dotar a la cocina de unas determinadas condiciones y de una serie de utensilios, había que asegurar su mantenimiento en orden y con la debida limpieza, procurando siempre el control de todo lo que se gastaba y consumía. Para ello se establecía la periódica inspección de la cocina por parte del veedor:

"Siempre ha de visitar la cocina el veedor semanero, para ver si se guisa con limpieza, y sazon, y no dar lugar a que aya desorden, y no consentir que haya picaros, que son causa de que no haya limpieza, y que aya mucha cuenta y razon con la leña, y carbon que en ella se gasta, como tengo ya dicho, y no consentir que se saque brasa, ni que se guisen ollas de fuera, ni que aya concurso de gente, y ha de estar la cocina, y erramientas muy limpio, y quando fuere puede reconocer si esto se haze assi. ${ }^{29}$

Cuestión esencial era el contenido, preparación y combinación de los alimentos. Productos, platos y menús constituían los factores fundamentales que determinaban un estilo de alimentación. Entre los productos esenciales, pan, vino y carne, el más básico era el pan. El pan era en la España moderna el alimento por excelencia, presente en todas las mesas, pero mientras en las clases populares el pan constituía el centro de su alimentación, en las clases acomodadas ocupaba un lugar secundario. Entre los numerosos y variados productos alimenticios que se habian de hallar disponibles en una gran casa nobiliaria, en opinión de Yelgo de Bázquez, el mayordomo debía tener especial cuidado con el pan, que era

\footnotetext{
*aelgo, 153v.-155v.

29 Yelgo, $11 \mathrm{v}-12 \mathrm{r}$.
} 
un alimento básico y simbólico, que nunca podía faltar en la mesa y que debía ser de la mejor calidad. Para la mesa señorial el pan debía ser de buena harina de excelente trigo, elaborado por buenos panaderos diariamente, es decir pan muy blanco y tierno. También debía cuidarse el pan de los enfermos. En general todo el pan que se consumía en la casa había de ser bueno, como correspondía a la categoría del dueño de la casa, independientemente de quienes fueran los que lo hubieran de comer, pues la calidad del pan, además de una cuestión de gusto, era un claro signo social:

"En lo que toca para el pan de la mesa del señor, se ha de procurar el mejor trigo que se hallare, y los panaderos que sean muy buenos, y cada dia se ha de cocer, y para los demas que comen del plato, y enfermos, ha de aver otro pan, que sea bueno, en que aura la cuenta y razon que contiene.

El pan de la gente ha de ser siempre bueno, y se deve tener mucha cuenta con que se haga assi, pues el pan, vino, y came, es justo que lo sean." "3o

Otro componente importante cran las bebidas, que no eran simples complementos, sino que formaban parte esencial de la alimentación y tenían sus propias particularidades, tanto en la preparación como en el servicio. Las bebidas principales eran el agua y el vino, pero existían además muchas otras clases de bebidas. También debía velar el mayordomo por las bebidas, procurando que fueran puestas a enfriar cuando conviniera, pues la afición a las bebidas frescas era muy grande en aquella época, mucho más en una casa de calidad, y hubiera sido un fallo imperdonable servir bebidas que no se hallaran en su temperatura adecuada. Circunstancia principal era asegurar la limpieza. Especialmente debía preocuparse por el agua, cuidando de que fuera de la mejor calidad, condición bastante dificil de conseguir en la época, pues no abundaban las aguas buenas, tanto para la salud como para el gusto, y todavía más difícil era conservar el agua en buenas condiciones hasta el momento de servirla a la mesa. Entre las bebidas se mencionaba especialmente las llamadas "aguas cocidas", que eran preparaciones a base de agua hervida con frutas, como limonadas o naranjadas, o con especias, como el agua de canela:

"En lo que toca a las bevidas, se ha de procurar en los tiempos, que este a enfriar con mucha limpieça, y que de ordinario aya la mejor agua que se pudiere, y conforme a las ocasiones, se tengan aguas cocidas, y que se sepan hazer bien, y con buena sazón, avisando al botiller."31

30) Yelgo, [0v-11r.

"1 Yelgo, 4v-5r. 
Si el servicio de una gran casa nobiliaria debía ser esmerado y de alta calidad, en consonancia debía estar la alimentación. A la mesa del señor no podía llegar cualquier guisote. La elaboración de los platos dignos de un gran señor era responsabilidad, naturalmente, del cocinero, que no podía ser un cocinero cualquiera, sino que necesariamente habia de ser un buen cocinero. Un buen cocinero debía saber cocinar muy bien y, sobre todo, debía saber cocinar muchos y variados platos. Porque la riqueza, el poder y la distinción de la alimentación señorial no sólo venía dada por la cantidad y la calidad de los alimentos, sino por la libertad del comensal, es decir por su permanente capacidad de elegir, de poder comer a su gusto, platos diferentes, sin verse sometido a los estrechos y rutinarios límites de la alimentación de las personas sencillas, obligadas por la falta de medios económicos, que no permitían ni la abundancia ni la calidad, y por la falta de tiempo o de habilidad, a comer platos sencillos y siempre repetidos. Comer es siempre elegir, pero mucho más para los ricos, poderosos y privilegiados.

Un cocinero de gran categoría no era el que se ceñía a los platos habituales, como el cocido, el asado o un plato de carne muy común en la España de los siglos XVI y XVII, el llamado carnero verde, que era un guiso de carnero con salsa verde de perejil. Y si era necesario dar variedad a la comida diaria, mucho más era necesario hacer un auténtico despliegue de medios con ocasión de alguna fiesta especial, como podía ser una invitación importante o la boda de un hijo, en las que la reputación de la casa exigía servir centenares de platos variados y sofisticados a los convidados y, por tanto, la reputación del cocinero de la casa precisaba saber preparar el banquete sin la vergüenza de haber de recurrir a un cocinero de fuera:

"Y el cocinero que se presiare de su oficio, ha de saver muchos guisados para diferenciar, que es mucha galanteria del cocinero y cobra fama, como el Doctor que tiene mucha medicina, que tiniendo necesidad el enfermo le aplique sesenta medicinas en un hora, que yo reniego del Doctor que no procura estudiar para estas ocasiones. $Y$ asi el cocinero no se ha de contentar con saber guisar un cocido, y un carnero verde, y un assado, sino mil platos si mil le pidieren, como suele suceder que el señor quiere combidar a otro, o casar un hijo: y quedariades afrentando si al tiempo de la ocasion fuesse menester buscar de fuera quien adreçase la comida: y el que fuere buen oficial de cocina ha de saber aderezar los guisados..."32

Ésta de la variedad era una de las cualidades del cocinero en que Yelgo de Bazquez insistía repetidamente. La capacidad de hacer muchos y buenos platos,

${ }^{32}$ Yelgo, 146r-146v. 
no iba sólo encaminada a satisfacer el gusto del señor y hacer honor a su reputación, sino que también era importante para cuidar de su salud y bienestar, sobre todo para abrirle el apetito en caso de hallarse desganado o inapetente: "Ha de ser el cocinero, hombre que sepa muchos guisados, y regalados, como dixe al principio deste capitulo: por si el señor pierde la gana del comer, las buenas sazones de los guisados, sus invenciones, se le abra la gana...."33

Un cocinero que dominara verdaderamente su oficio debía poder convertirlo en un arte y había de estar en condiciones de desplegar ante su amo y señor una larga y completa lista de platos, entre los que se hallaran los mejores de la época, elaborados con toda habilidad y dominio de las prácticas culinarias. Yelgo de Bázquez se muestra exigente con la categoría del cocinero que ha de servir a un gran señor y confecciona en su tratado, siguiendo la clásica dicotomía entre días de carne y días de pescado, derivada de los preceptos religiosos, una nutrida lista de platos variados, cames, pescados, sopas, potajes, salsas, empanadas, tortas, dulces.

Yelgo de Bázquez considera que un buen cocinero no puede estancarse en sus conocimientos habituales, sino que debe prepararse y mejorar continuamente, y para ello nada más adecuado que estudiar, inspirándose en las obras más importantes de otros cocineros célebres. Cita, como referencia obligada de todo cocinero que se precie, dos recetarios muy famosos en la época, uno español, el de Diego Granado, Libro del arte de cozina, en el qual se contiene el modo de guisar y de comer en cualquier tiempo, asi de carne, como de pescados, para sanos, enfermos, y convalecientes: asi de pasteles, tortas y salsas, como de conservas al uso Español, Italiano, y Tudesco de nuestros tiempos, ${ }^{34}$ publicado primero en Madrid en la imprenta de Luis Sánchez, el año 1599 y de nuevo en 1609 , y finalmente en Lérida en $1614,{ }^{35} \mathrm{y}$ cita también otro recetario de cocina italiano, el de Bartolomeo Scappi, ${ }^{36}$ Opera, cuya primera edición es de Venecia, 1570. Diego Granado en su libro copió y recopiló gran parte del tratado de Scappi. Scappi fue un gran cocinero italiano, "cuoco secreto" del papa Pío V, que, además de cocinar habitualmente para el pontífice, tuvo el honor de intervenir en la preparación de grandes banquetes de la época, ya en 1536, hallándose al servicio del cardenal Lorenzo Campeggi, tuvo la responsabilidad de cocinar un gran festín

\footnotetext{
Yelgo, 145r.

"Vid una edición actual, GRANADO, Diego: Libro del Arte de cozina, Lleida, Pagès, 1991.

"PÉREZ SAMPER, M" Ángeles: "Los recetarios españoles de cocina, siglos (XV-XVIII)" en Codici del gusto, Milán, Francoangeli, 1992, ps. 152-184.

"ALLARD, J.: "La cuisine espagnole au siècle d"Or" en Mélanges de la Casa de Velázquez, t. XXIV, 1988, ps. 177-190.
} 
para el Emperador Carlos V y en 1567 dispuso el gran banquete conmemorativo del primer aniversario del pontificado del papa Pío V.?

"Todo esto, y estas especies de guisados, y modos de conservas ha de saber el oficial de cocina para ser Massejuan, o Massepedro, porque nunca dexa menester entre año, que lo uno, que lo otro: y si dixesse el señor: Aderezadme tal guisado, sea de lo que fuere, si no la sabeis, llamar al mayordomo, y desgustado con vos, le reñira, que que cocinero tiene en casa, que le manda que aderece un plato que se le ha antojado, y dize que no lo sabe, que esto les suele suceder a los que pretenden ser escrivanos, que con el desseo que tienen de dar fees, plegue a Dios que las den finas, estudian quatro o cinco escrituras, las que les parecen que se usan mas, o las que sospecha que le pedira los señores del Consejo, quando se van a examinar, y es su desdicha, que luego le piden que diga una escritura, que no la han estudiado, ni se ha acordado della, y como no dize la que le piden, echenlo por la puerta a fuera, diziendole un portero: Salid hermano, salid hermano, estudiad en Monterrose, o en Ribera, esso mismo digo yo al cocinero, que procure dezir: No se, porque no le echen por la puerta a fuera, sino estudiar en Granado, o en Bartolme Caspi, que son dos libros muy curiosos, Granado en Español, y Calpi en Italiano, y alli esta como se ha de guisar todo lo sobredicho arriba dando entera sazon a cada diferencia de guisado, o conservas. Estos dos libros que dan entera razon del guisar, y como se llaman de cocina, ninguno del arte dexe de regirse por cualquier dellos, el Español, para Español, el Italiano, para Italiano":s

Como complemento a las referencias de los recetarios de Granado y Scappi se puede consultar también otro gran recetario español de la época, el de Francisco Martínez Montiño, publicado en Madrid en 1611, Arte de cozina, pasteleria, vizcocheria y conserveria. Cocinero de Felipe III y de Felipe IV su recetario, que refleja su experiencia cortesana, se convertiría en el más famoso libro de cocina de la España del siglo XVII y gran parte del siglo XVIII, modelo por excelencia que todos trataran de emular, siendo reeditado numerosas veces, 26 en esos dos siglos. ${ }^{39}$ Interesante resulta también el recetario de Hernández de Maceras, cocinero de un Colegio mayor de la Universidad de Salamanca, que pretendía reunir en su libro, publicado en 1607, una serie de platos "los más usuales y necesarios a las mesas de los Príncipes y Señores." ${ }^{40}$

37 SCAPPI, Bartolomeo: Opera, Venecia, 1570. Edición facsímil con presentación de Giancarlo Roversi, Bolonia, ed. Forni, 198I. Una selección de textos del tratado de cocina de Scappi puede hallarse en L'arte della cucina in Italia. Edición de Emilio Faccioli, Turín, Einaudi, 1987, ps. 419-463. "Yelgo, I53r-153v.

${ }^{32}$ Ediciones facsímiles actuales existen varias: Barcelona, Tusquets, 1982; Valencia, París-Valencia, 1994.

"PÉREZ SAMPER, M" Angeles: La alimentación en la España del Siglo de Oro. Domingo Hernández de Maceras "Libro del Arte de Cocina", Huesca, La Val de Onsera, 1998. 
En las listas de platos ofrecidas por Yelgo de Bázquez se detecta la influencia italiana, -platos a la romana, a la veneciana, a la genovesa-, fruto de las fuentes confesadas, el libro italiano de Scappi y el libro español de Granado, que también había copiado a Scappi. En cualquier caso la influencia italiana era notable en la cocina española de la época, resultado de las coincidencias derivadas do $I_{a}$ condición mediterránea de ambos países y de las estrechas relaciones de todo $t_{\mathrm{x}_{\mathrm{r}}}$ existentes entre España y los diversos estados italianos, muy especialmente en el ámbito cultural y también concretamente en el estilo culinario.

Yelgo de Bázquez dedicó el Capítulo XIX de su obra a establecer una larga lista de platos, que consideraba necesarios para el servicio de una gran casa y que, por tanto, debía poder esperarse que el cocinero los conociera y pudiera preparar con maestría: "Donde se le da cuenta al cocinero de las diferencias de guisados que deve saber para ser buen oficial" ${ }^{21}{ }^{41} \mathrm{La}$ simple lectura de la lista de platos resulta bien reveladora de lo que, a principios del siglo XVII, se consideraba en España la alimentación digna de una gran casa nobiliaria.

Comenzaba con una larga lista de platos de carne, el producto más valorado y más caro, elemento de distinción y prestigio social:

"Deve saber: Para dias de carne, emborrizar unos pavos, emborrizar unos capones, proete de madama de almendras, potage de lebrada, hazer escaveche de perdizes, una capirotada de perdices, una lebrada de pichones $\sin$ huesso, salchichones de verano, caçuela de manos de cabrito, o de ternera, un pecho de baca gordo con huevos, unas carbonadas con ave, unos artaletes con madreçuelas y yemas, y tripas de gallina, unas roelas de colas de carnero, un compuesto de colas de carnero, una riñonada de carnero, un plato de hijadas de carnero, unas torojas de carnero, unos pastelilos quaxados de ternera, un plato de ternera preparada, una dobladura de carnero, unos torreznos con vino, cardo guisado, manjar blanco, frutas de sarten, fruta de manjar blanco en empanadillas, un adovo de camero, un ogete para un ansaron, rorolas de ygados, un potage gue se llama yjada, un pastel en bote, conejos en escaveche, hazer una buena or uga, buena mostaça francesa, sopas a la lombarda, buena salsa galatina, caldo lardero de puerco, sopas doradas, pastelillos de caña de baca, empanadas de rodas fuertes, una salsa blanca de ansarones, guisado de queso a la Flamenca, assar una espalda de vaca en un asador, assarla en parrillas, guissar de todas carnes a la Veneciana, saber ahogar un lomillo de vaca en el horno, pastelones de lomillos a la Romana, pulpetas de lomillos rellenas, guissar unos pies de vaca que ay mil maneras, una ubre de vaca de otras tantas, una lengua de ternera assada, y rellena, relleno de came magra de ternera,

4) Yelgo, 147r-156v. 
albondigillas de la carne magra de la ternera, un relleno de cabrito, o liebre, o conejo, caldo lardero de venado, saber cocer una cabeça de javali, unos rellenos de carne magra de puerco, rellenos assados, rellenos cocidos con agua y sal, ahogar un capon, o gallina, que se ahogan de muchas maneras, saber cocer un capon en un estufador, saber assar capones, y gallinas, y pollos rellenos con parrillas, y sin ellas, saber assar el pabo que no se le han de sacar las tripas para que este tierno, saber hazer una pepitoria, saber hazer una olla podrida, una capirotada con queso, una ginetada para todas carnes, guisar una avellanada de ternera, unas escudillas de manjar blanco blando, una ginetada con yemas de huevos, un manjar blanco de almidon, almidon de carne, manjar blanco de requeson, potaje de harina y pan rallado, macarrones a la Romana, macarrones con yerro, fideos, buñuelos de pulpa de capon, tortas de yerbas a la Lombarda, buñuelos descubiertos, huevos y yerbas, escudilla de arroz, un potaje de trigo y cevada sin corteça, potaje de mijo o paniço machacado, potaje de harina de castañas, potaje de frisuelas con havas fiescas, potaje de garvanços con caldo, verças de caldo de carne, escudilla de repollo, verças Milanesas, una nogada, verças exprimidas a la Romana, lechugas con caldo de carne de diversas maneras, potaje de todas yervas, espinacas con caldo de carne, nabos a la Veneciana, guisar alcalchofas con caldo de carne, saber hazer turmas de tierra con pollos, rellenar calabaça, sopas a la Lombarda con caldo de carne, capirotada con caldo de carne, sopas de almendaras tostadas, tortadas de pan con rifion de ternera, sopa dorada frita, revanadas mantecadas, huevos de tocino, tortitas dobles, pasteles de todas suertes, empanar lenguas de vaca, un pastel de quixadas, y ojos y ocicos de puerco, pastel de lomo de ternera, pastel de pulpa de pierna de vaca, pastel de ubre de vaca, pastel de cabeça de ternera sin huesos y rellena, diferentes pasteles de lengua de ternera, pasteles de la papada de la ternera, pastel hojaldrado y liso de assadura de la terneta, pastel de menudillo de terneta, pastel de ygado de carnero, pastel de pulpeton, temera rellena, pastel de pulpetas de diferentes maneras, pastel de reñonada de ternera, pastel de cabeça de cabrito, pastel de ojos y orejas y turmas de cabrito liso y ojaldrado, pastel que llaman quartos de cabrito, pastel de cabrito montes, pastel de pierna de venado, pasteles de liebres, perdigones y perdizes y capones, y anades, en pastel de todas suertes, pasteles de tordos, y codornices, y pajaros menores, pastel de leche y ubre de vaca, tortadas de todas maneras, costrada del reñon y lomillo de la ternera, tortas de los pechos de los pichones y pollos, y tortolas y codornices, torta de pernil de tozino, torta real de pulpas de faysanes y perdizes, torta real de pulpa de pichones, torta de requesones cocida con caldo de carne, torta de tronchos de cardo, y alcalchofas de diferentes maneras, tortas de nuezes, torta de repollo, torta de de verças repolladas, torta de calavaça sin maçasorra de cenorias, torta de melones, torta de nisperos, torta de guindas y cereças frescas, torta de castañas verdes y secas." 
Seguía a continuación otra larga lista de platos para los días de abstinencia, sobre todo platos de pescado, verduras y cereales, productos menos valorados, que encontraban su sitio en la mesa como sustitutos de la carne:

Para dias de pescado. Saber poner el sollo a sudar o estofar pedaços, y guissarlo de muchas maneras, hazer escudilla, de pulpa de sollo con almendras, saber coçer a pedaços el sollo, saberlo cocer quando ha estado en adovo, saberlo asar en parrillas, hazer almondiguillas de pulpa de sollo, hazer rellenos de la pulpa del sollo, saber cocer la cabeça del atun con vino, coçer pedaços de atun en caçuela, cocer el atun con vino y agraz, rellenar pulpetones del atun, hazer un relleno de palomida que es un pescado del natural del atun, saber guisar un rovalo a la Veneciana, ques un pescado muy bueno, echar la embrina en escabeche, echar el corbo en escaveche, que es muy buen pescado, hazer potaje del pescado llamado orata, guisar fragolino, que es tan bueno como la orata, echar en escaveche el cefalo, hazer potaje de cefalo, cocer el cefalo, cocer el vesugo, guisar la salpa, que tiene el comer de la orata, cocer las ardas, echar en escaveche la sarda, almondiguillas de sarda, cocer el rodavallo que es muy buen pescado, asar el rodavallo, hazer gelea de rodavallo, hazer potaje de pescado llamado raja, echarla en caçuela, lamprea en parrillas, lamprea en escaveche, congrio fresco en caçuela, potaje de calamares, guisar el pulpo, guisar el pescado liamado palomo, guisar merluça, cocer pescado cecial, saber freyr el papagayo, que es muy buen pescado, empanar truchas, y echarlas en escaveche, cocer carpina, adereçar una tenca con nuezes, una escudilla de ranas sin huessos, saber rellenar los cangrejos, freyr la cambeta, aderezar unos ostiones en parrillas, o en horno, cocer el bonito, hazer manjar blanco de lucernas, agujas en escaveche, o en parrillas, assar el barvo en parrillas, almondiguillas de todos pescados, sardinas en escaveche, guisar caracoles, guisar salmon, hazer almidon de almendras, escudilla de arroz con leche, y sin ella, ginestrada de almendras, hazer calabaça, rellenar las verengenas, potage de hongos, espinacas fritas, eseudilla de azelgas, escudilla de achicorias, escudillas de esparragos, escudilla de bisaltos, lentejas secas, freyr macarrones, sopas de ciruelas pasas, sopa de hongos, sopas de criadillas de tierra, huevos entre brasa, huevos en tortilla, huevos con romero, huevos rellenos, huevos arrollados, huevos con yemas, huevos en caçuela, huevos rebueltos, empanadas de sollo, pastel de esturion, empanadas de obrina, empanadas de atun, empanadas de robalos, empanadas de besugos, pastel de rodaballo, pastel de raxada, pastel de lamprea, guisar calamares en caxa, pasteles de tortuga, pasteles de cangrejos, pasteles de ostiones, pasteles de caracoles, pasteles de truchas, pastel de ranas, pastel de anchovas y sardinas, pastel de pescado cecial, y otros pescados secos, saber hazer torta de higado de sollo, tortada de lamprea, tortada de cangrejos, tortada de atun, costrada de caracoles, tortada de tortugas, costrada de atun de hijada, tortada de hongos, tortada de turmas de tierra, tortada de 
mançanas de todas suertes, tortada de membrillos, tortada de duraznos, tortada Real de pichones y almendras, torta real de manjar blanco, torta de leche a la Romana, tortadas de queso sin masa a la Ginovesa, tortas verdes, torta de getas, torta de ciruelas pasas, torta canelada de maçapan, tortas de espinacas, torta de cardo, torta de garvanços, tortillas de arroz, frutas de vizcocho, yelo de pies de ternera, yelo de cabeças de cabrito, yelo de pies de carnero, yelo de hijadas, y ozico, y pies de puerco, yelo de todos pescados, xelea de membrillos.

Para terminar se añadían unas cuantas salsas para acompañar los asados, algunos otros platos variados y diversos postres dulces de conservas y confituras, muy apreciados por todo el mundo y especialmente por los paladares más refinados:

Salsas: salsa galatina, salsa de pavo, salsa de pasas, salsa de almendras, axada de nueces tiernas, salsa de zumos de granadas, salsa de ubas tintas, salsa real, salsa de zumo de membrillos, salsa de zumo de mançanas, salsa de agraz fresco, mostaça suave.

Platos diversos: pisto de pechugas de capon, tortas destiladas, pisto de pollos cocidos, pisto de ternera, pollos estofados, almondiguillas de pechuga de capon, pulpas de la ternera, potaje de pies de ternera y cabrito y pollos, potaje de turmas de camero y de turmas de temera, saber hazer un ordiate de cevada preparada, un proete de caldo de pollo, proete de preñadas, escudilla de huevos, escudilla de pan y leche, saber rellenar un pan grande, hazer una almendrada, pastelillos de ternera picados.

Conservas y confituras: conservas de limon real, rosa confitada, azucar rosado, azucar cubierto, ciruelas en aImivar, duraznos cubiertos, carne de alberchigos, carne de limon y patatas, azaar de azucar, çanaorias rellenas, tronchos de lechuga, hazer vizcochos, conserva de melon, conserva de costra de cidra, miel rosada, datiles en conserva, çanaoria encañutada, nuezes moscadas en azucar, peras en conserva, conserva de guindas, letuario de naranjas, bocadillos de membrillo, conserva de escorçonera.

Si importante era la elaboración de los platos, muy importante era también establecer el orden de presentación a la mesa. La confección del menú era una obligación que se hallaba a cargo del Veedor. Los sistemas alimentarios y mucho más los pertenecientes a las más altas clases sociales, que se hallan extraordinariamente codificados y ritualizados, no admitían el desorden. Una conida de calidad obedece siempre a unas reglas perfectamente establecidas, que deben respetarse y con las que hay que tratar de construir un conjunto equilibrado y armónico. Yelgo de Bázquez presentaba en su tratado un modelo de menú clásico en la época, compuesto por tres grandes partes. Primero los llamados "principios", que eran unos entrantes compuestos básicamente de vegetales, frutas y ensaladas, 
pero que podian incluir también productos del cerdo, como jamón y embutidos. En segundo lugar se servían los "platos", que constituían un conjunto muy variado, básicamente platos de carne, especialmente asados, pero también guisados, donde tenían un papel muy importante las empanadas, pasteles y tortas, preparaciones muy apreciadas desde la época medieval y que tenían una gran aceptación en la época moderna. En tercer lugar los postres, algunos salados, los más característicos el queso y las aceitunas, que entonces se servían al final de la comida, y otros platos dulces diversos, de huevos, frutas secas, frutas confitadas, las llamadas "frutas de sartén" o "frutas de hierro" o "frutas de embudo", a base de masa frita, confites de anís, que gozaban de extraordinario éxito entre todas las clases sociales de la época, comenzando por las acomodadas, que cran las que más frecuentemente podían permitírselos:

"Quando ordene la comida, empeçaran por los principios, y seran los que el tiempo diere: pero por no alargarme, pondre al Veedor esta comida, que es de todos tiempos, solo para que tenga luz de como lo ha de hazer, empeçando desta manera.

PRINCIPIOS: Vino bastardo con vizcochos, perniles de tocino de Garrovillas, o Aracena, o Rute, que son las mejores cecinas, guindas garrafales, limas dulces, melones, ubas, brevas, ensaladas labradas, manteca de bacas labrada, salchicon de Flandes, naranjas dulces frescas, mora, amaçenas, y ciruelas, y las demas frutas, la plaça os las enseñara, como tengo dicho, que es el mejor maestro.

PLATOS: Pavos assados, cubiertos a la Flamenca con salsa Real, gigotes de ternera en adovo, perdigones cubiertos, tortolas cevadas açeradas, artaletes de pechuga de capon, rellenos, perdizes armadas de sopa de natas, medias naranjas de mollete rellenas, conejos en huerta, cabrito encopetado, alfictetos de capones con maçapan, empanadas Inglesas de pichones, pastelones de lengua de vaca, torta de boca de dama, membrillos rellenos, piernas de carnero rellenas, pollos rellenos a la Francesa, mitraustre de gallina, costrada de orejones, molletes de queso fresco rellenos, empanada de francolines a lo vino, floretes de ternera, guirnaldas de carnero, bollos de Ribilla a la Portuguesa, pechos de ternera a la Flamenca, gansos rellenos, calabaça rellena, lechugas rellenas, lenguas de carnero emborriçadas, texeladas de leche y vizchos, quesos de caveças de javali, empanadas de venazon, platos de madrecillas rellenas, cabrito armado, empanadas de pechos de gallinas assados, salchichones de cueros de lechones, piernas de carnero estufadas, bollo arrollado en masa fina, pechugas de capones en medias lunas, piernas de carnero armadas, conejos a la Portuguesa, aves ensapadas, costradas de pie de puerco, xeleas de manos de cabrito agrias, palominos esparragados, plato de yemas y verdura y tocino magro, xigotes quajados de capones, pollos fritos en adovo, cabrito emborriçado, cardo relleno con riñonada, costrada de riñonada, pavos reales a lo vino, empa- 
nadas de conejos, empanadas de ternera fiambre, ojaldra de bollo de harina de arroz, pasteles ojaldrados, rollo de venado, espaldas de ternera enramada, conejos armados con cañas, pastelon de palominos con sus cañas, albondigas de ternera reales, pechos de ternera tostados y rellenos.

POSTRES: Huevos hilados de aletria, huevos mexidos, rellenos de pasta de maçapan, huevos mexidos de fratiquera, fruta de hierro de todas maneras, frutas de embudo, almojavanas de queso, fruta seca de açucar y huevos, luego los confiteros con anis, luego la camuesa, o peras, si las ay, o la fruta que huviere, y luego el queso y azeytunas.

$Y$ entender que postres y principios han de salir del botiller, que los ha de adereçar, que es el que enfria, y tiene en su poder la bevida, y aun la suele vender a los de afuera, mucho mas de lo que vale, pero no es mucho, pues buscan de lo caro." ${ }^{42}$

Junto a la cocina y los alimentos otro gran capítulo de la alimentación era la mesa, los objetos, los rituales. Entre los utensilios que se empleaban en el servicio de la mesa de los nobles, la mayor importancia la tenían los objetos de plata. La plata era uno de los signos de riqueza preferidos de la alta sociedad de la España de los Austrias. La alta nobleza poseía para adorno de sus casas enormes cantidades de plata labrada, una gran parte de esa plata se destinaba al servicio de la mesa, pues las vajillas de lujo de la época eran de plata. Para satisfacer esta demanda cientos de hábiles plateros trabajaban en toda España y especialmente en Madrid y su entorno más próximo, pues allí se concentraba la mayoría de los grandes señores, comenzando por el propio Rey.

En la platería española del siglo XVII destaca la riqueza y variedad de las piezas, muchas de ellas verdaderas obras de arte. Los inventarios dejan constancia del abundante número de tipos y de la originalidad de algunos de ellos, que incluso traspasaron las fronteras, influyendo en la platería de otros países. Lamentablemente son pocas las piezas no religiosas conservadas hasta la actualidad. Se labraron jarros, fuentes, saleros de torrecilla o simples, platos, cubiertos, tazas de pie alto, vasos, bernegales y tembladeras sobre salvas con pie, bandejas de servicio y de adorno, campanillas, perfumadores, candeleros bajos de base cuadrada o redonda, arañas, etc. Se crearon tipos nuevos, como el "taller" que consistía en una tabla o soporte en plata que sustentaba las siguientes piezas de un servicio de mesa: aceitera, vinagrera, azucarero, pimentero, salero y palillero. Otra pieza nueva era la llamada "mancerina", que se comenzó a hacer a fines de siglo, derivada del enorme éxito del chocolate. Se trataba de un plato o salvilla con abrazadera donde encajaba la jícara para el chocolate. Su fin era evitar que la jícara, que era de base muy pequeña, se volcara con facilidad y manchara los ves-

${ }^{42}$ Yelgo, 138v-140v. 
tidos. También fueron muy típicos de la época los candiles o velones con vástagos salomónicos, para iluminar sobre todo las mesas y aparadores. ${ }^{43}$ Yelgo de Bázquez, como veremos, cita en su libro unos cuantos ejemplos de las piezas de plata que solían existir en una casa noble, la mayoría de ellas relacionadas con la alimentación: fuentes, platos, salvillas, jarros, talleres, candeleros, copas, calderillas, barquillos, cantimploras, barriles, escudillas, braseros, pomos, tenedores, cucharas, saleros, pimenteros, azucareros, cantaros y aguamaniles.

Para cuidar y limpiar la plata existían en las grandes casas unos criados especializados que eran los reposteros de plata, que al tratar con objetos de gran precio, algunos de ellos verdaderas obras de arte, debían de ser personas muy honradas y de gran confianza. Yelgo de Bázquez en su obra sobre el estilo de servir a grandes señores no olvida a estos criados y dedica a establecer sus funciones y tareas en la casa el Capitulo XX, "Del modo de servir del Repostero de plata, y sus obligaciones". Comienza por destacar la necesaria fidelidad y honradez:

"El Repostero de plata ha de ser hombre de bien, y muy fiel, porque entra en su poder toda la plata labrada que tiene el señor para el servicio de su casa y mesa, y no es tan poco el valor della, que no vale treinta o quarenta mil ducados, sin la hechura, y porque toda esta hazienda entra en su poder, forçoso sera que sea de fiar, y hombre de verdad, que el que no la trata, no ay que admitillo en ninguna cosa de confiança, y porque se ha de hazer del, si jamas se ha hallado verdad, que es una cosa tan aborrecida a los ojos de la gente honrada, y a los de Dios, la mentira ningun hombre de verdad la amo..."44

Otras cualidades importantes del repostero de plata eran, en opinión de Yelgo de Bázquez, el cuidado y la limpieza, pues de ella dependía la buena conservación de las piezas de plata y su buen efecto, al procurar que mantuvieran todo su brillo y esplendor de nuevas, pues si la plata no se limpiaba adecuadamente y se trataba con descuido y negligencia se degradaba rápidamente. No era lo mismo la plata sucia y abollada que la pulida y resplandeciente, pues mientras la primera humillaba a la casa a la que pertenecía, la plata bien cuidada daba exactamente lo que se esperaba de ella, el brillo y el esplendor, que eran trasunto directo del brillo y del esplendor de su dueño:

"El Repostero de plata ha de tener gran limpieça con toda la plata que se le entrega, como son fuentes, y platos, salvillas, jarros, talleres, candeleros, y copas, calderillas, y barquillos, cantimploras, barriles, escudillas,

\footnotetext{
"FERNÁNDEZ, A. MUNUA, R. Y RABASCO, J.: Enciclopedia de la plata española y virreinal americana, Madrid, Asociación Española de Joyeros, Plateros y Rejojeros. 1984.

+4 Yelgo, 156v-157r.
} 
braseros, pomos, tenedores, cucharas, saleros, pimenteros, açucareros, y cantaros, y aguamaniles. Estas diferencias de hechuras de plata, y otras muchas mas, que por no ser prolixo no digo, tiene un repostero en su poder, $y$ assi tiene obligacion de que este con limpieça, y curiosidad que el que es buen repostero, ningun platero le ha de llevar ventaja en la curiosidad y limpieça, con que tiene la plata en su aparador, assi para que todo este con concierto, como para el buen tratamiento della: porque el repostero tiene obligacion muy particular de tratar bien la plata, que no este abollada, porque si la abolla, el mayordomo buscara otro que la trate mejor: porque ha de entender, que en cada pieça de las que tiene a su cargo tiene el señor puesto su gusto, y le han costado su hazienda, y assi deveys mirar que ninguna se tuerça, ni abolle, porque en viendola el señor assi, la querria mas ver quemada." ${ }^{945}$

Entre las obligaciones del repostero de plata figuraba, según Yelgo de Bázquez, la de asistir durante el servicio de la comida, para cuidar de la plata de la mesa señorial, con instrucciones muy detalladas sobre el modo de lavar y secar los platos, para asegurar su correcta limpieza y conservación:

"Tiene obligacion el repostero de plata a encender la chimenea, y braseros. Ha de tener cuydado quando el señor se siente a comer, tener una vacia grande con agua caliente junto al repuesto, o aparador donde se limpien los platos, que los pages sacaren de la mesa, y dalle al moço, o moços de plata dos paños, uno para limpiarlos quando los sacan del agua, otro para enjugarlos, y de manera, que quede el plato seco y sin pelusa para meterlo en la mesa, que por no saber limpiarlos, suele yr los platos, que para servirse dellos es menester tundillos, y esto sucede por ser el paño con que los enjugan de un anxeo muy ralo, y mal texido, que se le pega al plato las motas que tiene, como es mal hilado, que puesto en la mesa con los visos, señala muchas vedixitas, que muchas veces el señor dize, que no quiere de aquel plato, que el Maestresala parte por no comer en el plato, que es menester llevarlo a despinzar a Segovia, o a Baeça, y en este descuydo hallo quatro culpados, que cada uno de ellos peca de no muy limpio, le diera con el en la cabeça, no lo pondria: y si el page, quando le dan en la Reposteria un plato mal limpio, le dixesse al repostero, que era un sucio, y que no queria llevar essos platos a la mesa, el los hiziera limpiar mejor: pero callan, y viene corriendo de la mesa por un plato, o platos, y como dexan otro ojeado para lamello, porque otro no le coja el puesto, salen corriendo, y toman los platos, sin mirar si esta bien limpio, o mal y a las vezes le llevan mojado: y si el repostero, siendo culpa del moço de plata, cogiesse un plato, y le meneasse, el limpiaria mejor. $Y$ si el señor ve que los platos no se le ponen tan limpios como deven, le dixesse al maes-

${ }^{43}$ Yelgo, $158 \mathrm{v}-159 \mathrm{v}$ 
tresala, que mirasse los platos que se traen a la mesa, y esto con algun rigor, el maestresala tendria cuydado de reñir al page, y al repostero, y desta manera sera la mesa bien servida." ${ }^{\text {a6 }}$

Junto con la plata, otro elemento importante que debía estar igualmente a la altura del prestigio de la mesa señorial eran los manteles y servilletas. Comer directamente sobre la mesa era signo de pobreza y de falta de civilidad. Disponer de manteles y servilletas era señal clara de riqueza y de refinamiento. Si se trataba, como era el caso, de la mesa de un gran señor, los manteles y servilletas debían ser de la mejor clase, siempre blancos, generalmente tejidos de hilo y adamascados. En los siglos XVI y XVII, hasta la creación de la fábrica de la mantelería de La Coruña se consideraba que en España no se confeccionaba ropa de calidad digna de las mesas más selectas y tanto el Rey como los nobles principales compraban la ropa de mesa en el extranjero, sobre todo en Holanda. La ropa de mesa era variada y cada pieza cumplía una función determinada, había diversas clases de manteles, en las mesas de categoría se ponían normalmente tres, uno más sencillo directamente sobre la tabla, como protección, otro intermedio más fino, reservado para secarse las manos, después de retirar el primer mantel y de pasar el aguamanil al final de la comidas, y el mantel de encima de todo, que solía ser el más lujoso, pues era el que más se veía. Otras piezas del servicio de la mesa, tanto de utilización de los comensales, como de los servidores, el maestresala, los gentilhombres y los pajes, eran las servilletas, toallas, limpieças. Las servilletas de los niños recibían el nombre de "bavadores", es decir, baberos. Yelgo de Bázquez se ocupó en su obra del tema en el Capítulo XXI, "De las obligaciones del Repostero de ropa blanca":

"El repostero de ropa blanca tiene cuydado de toda la ropa del servicio de la mesa del señor, como son manteles, servilletas, toallas, limpieças, que por otro nombre se dizen, bavadores, y la diferencia que ay de bavadores a limpieças, es, servirles a los niños por las bavas, $y$ a los señores por la limpieça, y assi se deve llamar limpieça, las que estuvieren en poder del repostero, y bavadores, los que estuvieren en poder de un ama, que cria un niño. ${ }^{47}$

Si la limpieza era importante en el cocinero, en el repostero de la plata y en otros servidores, lo era en grado sumo en el repostero de la ropa blanca. En una casa importante toda la ropa de mesa debía ponerse limpia para el servicio de cada una de las comidas y cenas. Más bien por necesidad que por lujo, pues se consideraba, con toda razón, que poner manteles y servilletas usados y sucios era una auténtica grosería, que podía llegar a "revolver el estómago":

\footnotetext{
4i Yelgo, $159 \mathrm{v}-160 \mathrm{v}$.

${ }^{47}$ Yelgo, $161 \mathrm{r}-\mathrm{J} 61 \mathrm{v}$.
} 
"Ha de ser muy limpio el Repostero de ropa blanca, que siempre que pusiere la mesa, ponga ropa limpia, como son manteles, servilletas, $y$ toallas, y limpieça, y ha de tener una prensa, como diximos en el capitulo passado, donde despues de doblados los manteles, se aprensen, y hagan labor. Porque si se lo dixe al Repostero de plata, lo sepa hazer quando no huviere Repostero, ropa blanca, pero aviendole, a el le toca mas, y assi se lo digo, y esto con tanta limpieça, que enamore a todos los de la casa: porque si no lo es, de mala gana le tendran en ella, y para mi, lo peor que puede tener un hombre, o muger, es no ser limpios, porque donde no ay limpieça, rebuelve el estomago.' ${ }^{\prime 4}$

Aunque el cuidado de las mantelerias y las servilletas correspondia en las casas importantes, con muchos criados, cada uno con un oficio muy bien definido, a los resposteros de la ropa blanca, un repostero de la plata también debía hallarse en condiciones de ocuparse de la ropa de la mesa, en caso de ser necesario:

"Tiene cuydado el repostero de plata de ser muy curioso, que sepa coger las toallas y manteles, y aprensarlos para que hagan labor las dobladuras, porque aunque es verdad, que esto le toca al repostero de ropa blan$\mathrm{ca}$, no por eso se escusa de saberlo hazer el repostero de plata, porque podia estar en casa donde no huviere repostero de ropa, y lo hiziesse el todo." ${ }^{.49}$

Poner la mesa era un arte, pues estaba perfectamente regulado el lugar que debía ocupar cada una de las piezas de la vajilla y cada uno de los cubiertos y también la manera exacta en que debían estar dispuestos. Primero se colocaban, uno sobre otro, los diferentes manteles, hasta tres. Después las diversas piezas de plata, que además de tener una función práctica reunían también una función de embellecimiento y decoración de la mesa, saleros, pimenteros, azucareros. A continuación los servicios particulares de cada comensal, el "taller", una especie de bandeja plana, derivada de la antigua rebanada de pan que inicialmente servía de plato en las mesas medievales, sobre todo para cortar, -de ahí el nombre "taller", como en francés "tranchoir"-, y que en el siglo XVI comenzó a fabricarse en metal, especialmente en plata, y servía de base para colocar encima el plato y los cubiertos, sirviendo a la vez de protección de la mesa, como señal de respeto y como elemento de adorno. Sobre el "taller", el plato y los cubiertos, que eran tres, cuchillo, cuchara y tenedor, indicando la presencia del tenedor el máximo refinamiento en las maneras de la mesa, pues en esa época sólo se utilizaba en las mesas de mayor calidad y civilidad. El pan era individual y se ponía cubierto con la servilleta, lo cual también era un signo de distinción, pues sólo en las mesas popu-

${ }_{48}$ Yelgo, $162 \mathrm{r}-162 \mathrm{v}$.

49 Yelgo, 160v-161r. 
lares se comían rebanadas de grandes panes. La disposición de todas las piezas era cuidadosamente ordenada:

“... ha de tener cuydado (el repostero de ropa blanca) con las sobremesas, y poner la mesa desta manera. Primero la sobremesa, y luego unos manteles, y luego otros encima, para que en alçando la mesa, quedenlos de debaxo para dar agua manos, y puestos los manteles, lo primero pondra el salero, o saleros, y a un lado el pimentero, y a otro lado el açucarero, y luego empeçara a poner servicios, empeçando por la cabecera, baxando por el lado derecho de la mesa, terna cuenta, que los servicios que se pusieren a un Grande, o Grandes, sea en taller, y no en plato, y encima del taller un tenedor, y un cuchillo, y una cuchara, y advertir, que el tenedor se ha de poner a la mano izquierda, y la cuchara, y el cuchillo, se ha de poner a la mano derecha, y puesto esto por el orden dicho, pondra su servilleta encima del pan, y luego cubritalo, poniendo encina del taller un plato boca abaxo, que este cubierto el servicio, que es ceremonia, por donde se conoce el que es Grande, quando se va a sentar a comer, y en esso se conoce el que es Grande delante del Rey, en estar cubierto, y advertir, que en el taller del señor, en la una esquina ha de tener su salero, porque tiene quatro esquinas. ${ }^{\text {sin }}$

Muy interesante es la transposición que se hace del privilegio de cubrirse ante el Rey que distinguía a los Grandes de España al modo de disponer el servicio de mesa que les corresponde, que también debía estar cubierto por un plato, para indicar inequivocamente que aquel lugar estaba reservado a un Grande de España, como un signo más de la función social de la mesa que marca las jerarquias, tratando de reproducir y señalar las diferencias de la sociedad sobre la mesa, una mesa que a la vez une, pues comer juntos es señal de pertenecer de alguna forma al mismo grupo, y también separa, pues no es lo mismo el lugar que se ocupa y los detalles que marcan las distinciones entre unos y otros comensales. A través de las reglas de la etiqueta, se pretende que la mesa sea un fiel reflejo del orden social. La función del repostero de ropa blanca, que era el encargado de poner la mesa, debía ser supervisada por el maestresala, insistiendo Yelgo de Bázquez en la etiqueta correspondiente a los Grandes de España:

"Tendra cuydado el Maestresala de hazer al repostero, quando le mande poner la mesa, que cubra el servicio del señor, si fuere grande, poniendo un taller debaxo, y luego el pan encima, y arrimado al pan un cuchillo, y al lado yzquierdo un tenedor y una cucachara, y luego un plato, que lo cubra: porque si ay combidados, echen de ver qual es el servicio del Grande, que alli se echa de ver no aver otro cubierto, y en esto se conoce

\footnotetext{
"1) Yelgo, 161 v-162r.
} 
un Grande de España delante del Rey, en estar cubierto, y los demas cavalleros destocados. Y si a caso combidase el señor a otro Grande a comer, tambien le ha de cubrir el servicio, y uno de los cubiertos ha de poner a la cabecera de la mesa, y el otro al lado derecho, para que el señor regale al huesped con el mejor lugar, que siempre a los huespedes, se les ha de dar lo mejor, sea en la mesa, o siendo de passeo por la calle.,"s1

El arte de servir la mesa era elemento sobresaliente en el arte de servir a los Grandes. El ritual de la mesa era un acto simbólico, casi litúrgico, uno de los actos de la vida cotidiana que se pretendía que definiera la calidad del estilo de vida noble. El ritual del servicio, tal como lo presentaba Yelgo de Bazquez en su tratado, era muy parecido al ceremonial borgoñón que se estilaba en la Corte desde tiempos del Emperador Carlos, lo que confirma claramente el papel de modelo que la Corte jugaba con respecto a la nobleza, que trataba de imitar en su comportamiento privado y público el ejemplo del monarca y su entorno más próximo. ${ }^{52}$ La Corte era el punto de referencia obligado, que se consideraba como ideal y que se intentaba reproducir en la medida de las posibilidades, aunque fuera a una escala algo más modesta y reducida, pues además de la dificultad económica que suponía, era una cuestión del respeto debido al Rey, a su poder y majestad, no competir con el esplendor de su casa.

Al tratarse de un momento importante del servicio al señor, en el ritual de la comida era necesaria la presencia del más importante de los servidores, el mayordomo. El mayordomo encabezaba todo el ritualizado proceso de servir la mesa. El acto de comer, por la importancia que se le concedía, requería, de entrada, un contexto apropiado y elegante. El mayordomo, con la autoridad que tenía sobre todos los criados, era el responsable de crear y mantener un ambiente acogedor y armonioso, un clima de tranquilidad, propicio para la comida y para la conversación en la mesa. Había que establecer y cumplir una correcta organización, para evitar gritos, ruidos, desorden y desconcierto, que podrían perturbar el ambiente y, por tanto, la comida de los señores: "Ha de tener mucho cuydado, que en la sala, ni en otra parte aya bozes ni ruydos, ni en las oficinas, sino que aya mucha quietud, dando orden con tiempo, pues con saber cada uno lo que ha de hazer, se escusara ruydo.".53

En el servicio de la mesa, junto al mayordomo, la principal responsabilidad recaía en el maestresala, según lo definía Yelgo de Bázquez: "El Maestresala es

\footnotetext{
s Yelgo, 38r-38v.

52 PÉREZ SAMPER, M" Ángeles: "La mesa del Rey. Imagen y simbolo del poder" en Actas del XV Congreso de Histaria de la Corona de Aragón. Tomo I El poder real en la Corona de Aragón (Siglos $X I V-X V I)$, vol. $3^{\circ}$, Zaragoza, Gobierno de Aragón, 1996, ps. 433-449.

s3 Yelgo, 4v.
} 
un oficio muy honrado, de quien cuelgan todas las ceremonias de criança y cortesia de la mesa, y de la sala, porque esso quiere dezir Maestresala, maestre de la sala.... ${ }^{34}$ El maestresala dirigía, pues, el servicio de la mesa, de acuerdo con las complicadas normas de la etiqueta. Cada gesto y cada acción estaban perfectamente calculados y codificados. El servicio de la comida se convertía por influencia de la etiqueta en una especie de procesión, de la cocina al comedor, en que el alimento era portado y acompañado de manera ceremonial por los servidores, tanto por razones de etiqueta como por razones de seguridad:

"Y quando entraren (en la cocina) los oficiales, y pages por la comida, no se ha de consentir que los pages esten cubiertos, ni los cocineros, ni se ha de echar la comida antes que vayan por ella, sino de alli adelante, despues que los oficiales esten presentes. $Y$ aviendo de subir el cocinero la comida, vaya detras de los pages con su toalla limpia."

"Han de baxar de ordinario por el plato el Mayordomo, y Maestresala con los pages, y el Veedor subira detras de la comida, y en la cocina ha de aver una mesa con sus manteles limpios, donde se han de poner los platos, y despues de subidos, los pondran en la mesa del señor el Mayordomo, y Maestresala, y con el primero servicio entrara el Mayordomo delante, y ni mas ni menos con todos los platos que fueren viniendo despues, con que se va cevando la mesa, y los platos que se huvieren de traer de la comida, despues de subida la comida, conforme a los que huviere, baxaran los pages que fueren menester, y el Veedor baxara y subira tras dellos...?

En el servicio de la comida era muy importante mantener el orden establecido de los platos, según los complicados menús confeccionados para cada comi$\mathrm{da}$, lo cual no era fácil si no existía una buena organización, pues los platos eran muchos y diversos, sobre todo en los banquetes, en los que se acostumbraban a servir en las grandes casas cientos de platos y no era raro equivocarse en el orden de tomarlos en la cocina o de servirlos a la mesa, ya que eran muchos los implicados:

"El Maestresala deve mirar, que la comida vaya con concierto, que no vaya detras lo de adelante, sino que vaya haziendo platos como vinieren de la cocina ordenados del veedor, y cocinero, empeçando por la fruta, dando por principios las frutas acedas, y las demas que arrojare el tiempo, dando por postres las conservas, dulces, y frutas de sarten."'s:

\footnotetext{
"Yelgo, 33v.

"Yelgo, 12r.

"Yelgo, 5r-5v.

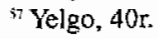


La limpieza en el servicio era muy importante y se debían cuidar todos los detalles, como cubrir las frutas para que no pudiera caer polvo o insectos, o sostener los servidores los platos con paños limpios para evitar ensuciarlos o sudarlos:

"Tendrà cuydado el Maestresala de avisar al repostero, que quando ponga las frutas para empeçar a comer, que las cubra con un confitero, de modo, que no tenga lugar las moscas de entrar, ni el polvo. Esto de cubrir las mesas, por pobres que sean parece bien la limpieça."\$B

"Tendrà cuydado el Maestresala, en sentandose a comer, que un page trayga dos fuentes para descubrir la mesa, y tomara el Maestresala el confitero, y lo pondra en una fuente, y lo cubrira, con la otra haziendo una reverencia. El Maestresala ha de tener siempre una toalla en el ombro izquierdo, para meter con la mano derecha, quando se ofrezca: hara en empeçando a comer, que se ponga un page, el mas moderno de todos, con un paño al ombro, como modo de toalla, prendido con un alfiler al cuello, $y$ tendrà los platos en el paño, porque es groseria tenerlos en las manos, porque sudan los platos: algunos Maestresalas ponen los platos junto a donde trinchan, y no es policia, sino que esten a manos, alçado el paño por las dos puntas, tiniendolos en el. El Maestresala los tendrà mas a mano para el servicio de la mesa...."s9

Para ayudar en el servicio el maestresala contaba con la asistencia de otros servidores, especialmente los gentilhombres y los pajes. Según advertía Yelgo de Bázquez, entre sus múltiples funciones de acompañamiento y servicio los Gentilhombres debían estar siempre presentes a las horas de las comidas de los señores para servirles: "Todas las comidas y cenas no faltaran de la mesa." Gentilhombre era el encargado de presentar los platos al señor y los demás comensales. Yelgo insistía en el servicio con la mano derecha, interpretando el gesto de la etiqueta como un simbolismo, la mano derecha representaria la nobleza y la bondad, mientras la mano izquierda significaría la bajeza y la maldad: "Tendra cuydado, de quando este sirviendo a la mesa no meter jamas la mano izquierda, sino todo lo que tomaren, o dieren, ha de ser con la mano derecha, y es muy bien servir con la mano derecha, que el que no sirviere a derechas, mal servira, y nunca acertara." ${ }^{\text {"6l }}$ A los pajes, que realizaban las funciones secundarias, el maestresala debía encargarse personalmente de enseñarles el oficio de servir al señor, con toda elegancia y cortesía:

\footnotetext{
58 Yelgo, 38v.

5o Yelgo, 38v-39r.

6i) Yelgo, $101 \mathrm{r}$.

6! Yelgo, 102r.
} 
"El Maestresala tiene de enseñar al page de la manera siguiente, que no meta las manos en las faldriqueras delante del señor. Enseñarles como han de servir a la mesa, en que mano han de llevar la copa, y en que ombro la toalla, con que mano tomarà, ò pondrà el plato en la mesa, y como han de dar agua a manos, y quando han de hablar, y quando han de callar, todas estas son cosas que el Maestresala las ha de saber por fuerça para enseñarlas, porque si no las sabe, mal podrá enseñarlas, y assi sera menester que se lo vamos diziendo al Macstresala, para que lo enseñe: diziendole al page, que cuando estè en la mesa, que no hable jamas, aunque de lo que se hablare sepa el mejor que nadie. No ha de despegar la boca hasta que se lo pregunten. Quando alce algun plato, metera la mano derecha, y tomara el plato del señor, y metera la mano por debaxo, passandolo a la mano izquierda, y con la derecha pondra el linpio, y se saldra haziendo una reverencia, y siempre tendra un plato limpio en la mano, arrimado al pecho, el suelo del plato hazia dentro, y el fondo hazia fuera, para darselo al Maestresala, o ponerlo en la mesa, aunque los pages no han de meter los platos en la mesa: y si los pusieren, han de ser a necesidad, como es aviendo un banquete, que no pueden aver tantos criados como señores, que en tal caso meten la mano los pages en ella, que aviendo criados, ni por imaginacion la han de meter, y quando traxere agua manos, han de llevar la fuente en la mano derecha, y el agua en la yzquierda, y en llegando a la mesa, tomara la fuente un gentilhombre, y pondrala al señor, arrojando debaxo una toalla, esto se entiende, si el repostero no huviese puesto manteles, que se suelen poner debaxo de los que se tienden para comer, en tal caso se ha de echar la toalla, que si los ay no es menester echarla."162

Tampoco descuidaba Yelgo de Bázquez, previsor al máximo, de regular el modo de iluminar el comedor y la mesa por las noches, para la cena: "Tendra cuydado (el maestresala), de que cuando trayga la cena al señor, que venga con dos hachas delante encendidas, y se quedaran una pieça mas atras, do estuviere la mesa, y alli juntos se quedaran." ${ }^{13}$

Cuestión fundamental en el estilo noble de servir la mesa era el arte de trinchar la carne, el corte de las aves y de las piezas de carne, que en las casas de categoría no se hacía en la cocina, sino que se hacía en la mesa, ante el señor y todos los comensales. El asado de piezas enteras era el plato principal de toda comida de calidad. Pero este plato entrañaba una gran dificultad en el modo en que debía ser troceado. Desde luego, no podía ser despedazado de cualquier manera. No lo permitía el arte culinario y mucho menos las buenas maneras de una mesa de calidad. No era una tarea que pudiera hacer cualquiera, por hábil que fuera, ni siquiera el cocinero. Puesto que era un servicio personal y directo al

\footnotetext{
re Yelgo, 35v $-36 \mathrm{v}$

"Yelgo, 37r.
} 
señor se consideraba que debía realizarlo una persona de calidad, un caballero. De ese modo, a medida que fue avanzando el proceso de civilidad y refinamiento, especialmente en las cortes medievales y renacentistas, el corte de la carne asada se convirtió en un verdadero arte, signo de nobleza.

E1 caballero trinchante ocupaba un lugar de honor en el ceremonial de la mesa desde la edad media. No sólo había de ser un hombre de la mayor confianza del Señor, sino que como buen cortesano debía ser un hombre hábil que cortara las piezas con elegancia y aprovechamiento. En una época en que los comensales no disponian más que de un cuchillo, pues el tenedor fue poco frecuente hasta el siglo XVIl y no se difundió ampliamente hasta el siglo XVlll, era importante que el encargado de trinchar la carne lo hiciera muy bien, porque de esa forma la pieza servida se aprovechaba mucho mejor y bien cortada resultaba mucho más tierna y sabrosa.

La importancia del oficio de trinchante queda bien de manifiesto en múltiples textos, por lo que se refiere a España se puede comenzar citando el Libre de Sent Soví, recetario de cocina manuscrito de comienzos del siglo XIV, que incluya varios capítulos sobre el tema. ${ }^{64}$ Destaca especialmente el famoso Arte cisoria de don Enrique de Villena, ${ }^{65}$ escrito en 1423, dedicado totalmente al arte de cortar, como su título indica, libro que se convirtió en modelo por excelencia de la elegancia cortesana en el difícil arte de saber cortar la carne al estilo de los caballeros. También trata el tema el Mestre Robert en su Libre del Coch, ${ }^{66}$ escrito a fines del siglo XV y publicado por primera vez en catalán en 1520, Ruperto de Nola en la versión castellana del recetario, la primera de 1525 , titulada Libro de guisados, manjares y potajes. ${ }^{67}$ A fines del siglo XVl Diego Granado no olvidó tampoco el tema, dedicándole el capítulo 13 de su Libro del Arte de cozina: "Del corte de las carnes". ${ }^{68}$ A comienzos del siglo XVII el cocinero de Felipe III, Francisco Martínez Montiño en su famoso recetario de cocina cortesana trataba la cuestión de cortar y presentar las aves, pavos, lechones y liebres en su Arte de Cocina, pas-

${ }^{64}$ Libre de Sent Sovt. (Receptari de cuina). Edición e introducción de Rudolf Grewc, Barcelona, Ed. Barcino, 1979, ps. 74-84.

6: VILLENA, Enrique: Arte cisoria, Edición y estudio de Russell V. Brown, Barcelona, Editorial Hunanitas, 1984. Otra ed. MARTiN, J.L., Salamanca, 1997.

thi Libre de doctrina per a ben servir de tallar y de l'art de coch, ço és de qualsevol manera de potatge y salses. Compost per lo diligent mestre Rabert, coch del serenissimo senyor Don Ferrando, rey de Nàpols, Barcelona, 1520. Edición actual: Mestre Robert, Libre del coch, Barcelona, Curial, 1982, ps. 25-30.

"7. Edición actual facsímil de la edición de Logroño de 1529, Valencia, París-Valencia, 1985. Otra ed. reciente, Huesca, La Val de Onsera, 1994.

in GRANADO, Diego: Libro del Arte de cozina, Lleida, Pagès, 1991, ps. 25-30. 
teleria, vizcocheria y conserveria, pero lo hacía con un sentido diferente, pues no se refería al arte de cortar en la mesa, ante el señor, sino en la cocina. ${ }^{69}$

Yelgo de Bázquez en su tratado sobre el estilo de servir a grandes señores, recogía la larga tradición cortesana del arte de cortar y confiaba el encargo de trinchar al maestresala, como director del servicio de la mesa, señalando que se dispusiera de un lugar especial y de utensilios adecuados, recomendando un cuchillo resistente, para poder hacer su oficio con garantías:

"Mandarà el Maestresala, que donde se ponga a trichar, que le pongan un plato con una servilleta, un tenedor, $y$ un cuchillo, de un poquillo de mas fuerça que los de los servicios de los señores, para que pueda tener fuerça para cortar, y aparar las aves, que por descuydo vinieren a la mesa por aparar, y para hazer platos, y servir la mesa." ${ }^{\text {"7o }}$

Hay que señalar, además, que no sólo se daban instrucciones muy precisas del modo de cortar la carne, sino también de la manera de servir, incluso de la preparación culinaria adecuada, por ejemplo, la salsa o condimento que debía acompañar el asado. Esta tradición se confirma plenamente en la atención que Yelgo de Bazquez dedicaba al tema, dedicándole todo el Capítulo V. De como ha de aparar el Maestresala las aves, y las carnes, y los cortes dellas."

El pavo se ha de cortar desta manera, quitando el pescueço, y la cabeça, y despues arrancar la cola, y quitarlelos pies, y luego el halon, y despues la pierna derecha, cortandola menudo y luego dar un corte en la tetilla derecha, y sacar tajadas anchas, y delgadas, y despues hazer lo mismo del otro lado sobre el obispillo.

El capon se corta de la manera del pavo, salvo, que las piernas, y pechugas no se han de cortar menudo, sino un golpe por arriba, y otro por debaxo, y meter el cuchillo por medio, y despues las pechugas, dando un corte a la larga, y sacar sus tajadas, y luego descoyuntar el ombrito, y sacar el huesso del pecho, y hazer otro tanto del otro lado, y esto se entiende en quanto a los capones y gallinas.

Las perdizes se cortan desta manera, primero los halones, y despues las piernas, y no del todo, sino abrirlas solamente para meter la sal con el cuchillo, començando por la pierna derecha, y despues por la pechuga, y meterle sal, y otro tanto a la otra parte, y luego abrirle las caderas, y poner

\footnotetext{
${ }^{69}$ Barcelona, Tusquets, 1982; ps. 421-425.

"Yelgo, 40r.

7 Yelgo, 44v-47v.
} 
lo mismo, y despues los cuartos delanteros, con el lomo, cortallos de dos en dos costillas, y despues partir la cabeça por medio, de manera que se puedan comer los sesos, echandoles pimienta.

La vaca se ha de cortar desta manera, cortando muy menudo, $y$ muy delgado, que parezca acepillado, reparando, que el corte no sea al reves, y por lo magro mezclado con lo gordo, advertir, que toda la carne que esta cerca del hueso es mas tierna, que no la otra, salvo la carne del lechon, que es mejor la del cuero. Y cortada la baca, hazer platos della, sembrando sal con un cuchillo, y echar sobre ella un poco de caldo, y si es magra echarle caldo gordo, y si es gorda, echarle caldo magro, y sin gordura. Y si la carne de la baca fuera gorda, ha de cocerle sin echar ninguna cosa con ella, ni tocino, ni especias, ni otra carne, sino solo pergil y yerva buena.

El tocino se ha de cortar desta manera, que venga el cuero del tocino hazia la parte del que lo corta, advirtiendo, que no lo cortes al traves, porque se deshilara, y cortar tajadas menudas, y delgadas.

El lechon se ha de cortar de esta manera, començar por la oreja derecha, con la espalda juntamente, cortar el cuero hasta la cadera, y de aquello cortar a voluntad del señor, si lo quiere menudo, o a tajadas medianas, o grandes, y lo mismo hara de la otra parte, de manera, que quede bien aparado, y de todo el cuerpo servir platos, y despues cortarle la cabeça con el pescueço todo junto, y despues quitarle las caderas, hasta los riñones, a manera de cabrito, y clespues cortarlo, a la voluntad del señor.

Paralelamente al ceremonial de la comida se desarrollaba el de la bebida. La bebida era generalmente vino, salvo alguna rara excepción, pues la bebida por excelencia de la época, sobre todo para acompañar las comidas, en todas las clases sociales era el vino, de mayor o menor calidad según los casos, y tratándose de una casa de la alta nobleza puede afirmarse sin lugar a dudas que se trataría de la mejor calidad. Las bebidas y las copas en que debían ser servidas no se hallaban habitualmente en la mesa principal donde se hallaban los comensales, sino que igual que sucedía en la Corte, se hallaban en un mueble auxiliar, el aparador. En ese aparador se colocaban las jarras y copas, tanto para el servicio como para la ornamentación, pues normalmente se trataba de jarras y copas de metales preciosos o de vidrio decorado y su presentación, junto con la de bandejas, platos y otros utensilios, igualmente lujosos, de plata, oro o porcelana, desempeñaban un papel de escaparate de la riqueza y el buen gusto del dueño de la casa y contribuían a adornar la sala que servía de comedor. El Mayordomo supervisaba la organización, pero de la función concreta de servir la bebida se encargaba el "botiller". Las copas y jarras se tapaban cuidadosamente con servilletas limpias, para evitar que algo pudiera caer en la bebida. Era importante que todo estuviera dispuesto con antelación, para ahorrarse incómodas idas y venidas, que perturbaban el buen orden de la comida, entendida como una ceremonia: 
"... quando baxen por la comida, se ha de mandar que suba el Botiller, y llene todo el recaudo necesario para el servicio de la bevida. $Y$ en el aparador hara que esten las servilletas necesarias cubiertas para la bevida, como diremos en el oficio de gentilhombre de copa, para que no sea menester yr por ellas a la reposteria, conforme a los que huviere de mesa, a los quales se suele servir con ellas. Ha de visitar el aparador, y veer si esta bien puesto, y con limpieza, y conforme a los que huviere de mesa, y aya las copas, y basijas necesarias, para que no bevanlos unos en las de los otros, ni sea menester yr al aparador, ni a la reposteria por ellas." ${ }^{\text {"n }}$

Las bebidas, pues, habian de estar convenientemente dispuestas en el aparador, para cuando los comensales solicitaran beber. La ceremonia de servir la bebida era igualmente complicada y reverencial: "Quando truxeren la copa al señor, quiriendo bever, haran una reverencia todos los que estuvieren presentes muy baxa, y la tendran hecha, hasta que acabe de bever."7?

El maestresala era también el encargado de dirigir la ceremonia de la bebi$\mathrm{da}$, en la que seguía teniendo como en la época medieval un papel relevante la salva, que era el acto de probar previamente un servidor, en este caso el gentilhombre de copa, la bebida, como medida de seguridad para evitar ofrecer al señor bebidas en malas condiciones e incluso para ponerlo a salvo de envenenamientos intencionados, pero que ya en el siglo XVII, como indica claramente Yelgo de Bázquez, tenía un marcado carácter de respeto. La salva era tanto el acto de la prueba en sí, como el plato en que se realizaba la prueba:

"Tendrá cuydado (el maestresala) quando el señor pida de bever, haziendo que un gentilhombre venga con una servilleta detras de la copa, cuvierta con un plato, o salva, y en acabando de bever el señor, metera el braço derecho con la salva, levantando el plato con la yzquierda para que tome la servilleta el señor, haziendo el criado una teverencia muy baxa, y luego que tome la servilleta, que ponga la otra encima de la salva, se levantarì, y antes que buelva las espaladas hara una reverencia, levantando hacia arriba la salva al son de la reverencia baxar las manos con ella, lo mismo hazer el que truxere la copa, y no digo al gentilhombre de copa que haga salva, porque aunque es grandeza, no la quieren usar, pero si quisiesse por algun respeto, es bien que lo sepa el Maestresala para que lo enseñe, salva es, quando le traen de bever al señor, traer la copa en la mano derecha, y la salva en la yzquierda: y quando el señor quiera bever, echara un poqui-

\footnotetext{
"2 Yelgo, 5v.

${ }^{73}$ Yelgo, 36v-37r.
} 
to de bevida un traguito solo en la salva, y beveralo, que es dar fe de que viene sana la bevida." ${ }^{34}$

Aunque el maestresala dirigía el ritual de la bebida, el principal protagonista de este servicio era un gentilhombre que tenía asignado de manera especial este oficio y al que Yelgo de Bázquez dedicaba el capítulo XII, "Del modo del servir del Gentilhombre de copa, y sus obligaciones", insistiendo en todos los detalles de este servicio, sin duda uno de los más emblemáticos del ritual de la mesa, precisando cuidadosamente cada palabra, cada movimiento y hasta el menor gesto:

"Ya tengo dicho al maestresala el modo de dar la copa, pero no me escuso de dezirlo aqui al Gentilhombre que le ha de dar, distintamente.

El Gentilhombre que da la copa al señor, se llama Gentilhombre de copa, tiene cuydado de que quando el señor pida de vever, respondera, haziendo una reverencia muy baxa, en que copa quiere vever V. Excelencia? respondiendo el señor en tal, o en la que os pidiere, deshara la reverencia de passo de modo, que el cuerpo, y el pie vaya saliendo a un tiempo, y yra por las vevidas". ${ }^{75}$

Una vez que se hubiera servido la bebida contenida en la jarras dispuestas en el aparador, la copa era llevada a la mesa y entregada al señor con tal cantidad de reverencias y genuflexiones que el acto común de beber una copa de vino quedaba tranfigurado en una especie de comunión simbólica:

“... entra la copa, ha darla al señor, hazicndo una reverencia al entrar de la pieça de passo sin pararse, emparejando con la mesa otra, y advertir, que quando la trayga, trayga una servilleta otro Gentilhombre, para que haga lo que le dire en acavando el señor de vever llegase con la copa, haziendo una reverencia junto al señor, y parado hara otra, quando el señor la fuere a tomar para bever, tenga en la mano derecha, y darsela: esto de tomarla se entiende que ay algunos, que llevan la copa en la salva, y otros en la mano, lo mejor es y mas seguro, que la salva vaya en la mano yzquierda y la copa en la mano derecha, y quando el señor la vaya a tomar, hincara la rodilla en el suelo, y tomara la copa con la mano derecha, y darsela al señor, y luego passara la salva de la mano izquierda a la derecha y la tema mientras el señor beve debaxo, como que recibe en ella las gotas de agua, o vino que cayere. $Y$ acabando de bever, bolvera de presto a passar la salva a la mano yzquierda, y recibira la copa en la mano derecha, del modo que la dio, y luego se levantara, haziendo una reverencia muy de espacio, baxando la rodilla un poco, assi como reverencia de viejo, que llama el vulgo, por ser la mas Cortes, aunque no la mas ayrosa, y bolvera

\footnotetext{
${ }^{74}$ Yelgo, 37v-38r.

${ }^{75}$ Yelgo, 99r-99v.
} 
haziendo otra reverencia, como de media Luna, bolviendo el cuerpo para salirse. $^{76}$

Otra advertencia adicional de Yelgo de Bázquez era que la bebida se sirviera por la izquierda del comensal, para facilitar que éste la pudiera tomar con comodidad la copa con la mano derecha: "Ha se de tener cuenta, que ha de llegar siempre el Gentilhombre de copa a darla con el lado yzquierdo, porque el señor la tome mas a placer con la mano derecha."

El Gentilhombre de la servilleta, era el que acompañaba al Gentilhombre de la copa, para que el señor se pudiera limpiar la boca después de haber bebido:

"Ha de advertir el que lleva la servilleta detras de la copa, que en acabando el señor de bever, que apenas aya tomado la copa el Gentilhombre, quando luego in continente meta el braço derecho con la servilieta limpia, y tomarla el señor con la mano derecha, y pondrala encima de la salva la que tenia con la mano yzquierda. Recebida la servilleta, se levantara haziendo las mismas reverencias que ha hecho el Gentilhombre de copa., ${ }^{\text {9 }}$

Aunque el servicio de la copa era altamente especializado y normalmente se encargaba el gentilhombre de la copa, en opinión de Yelgo de Bázquez todos los gentileshombres debían estar preparados para desempeñarlo a la perfección, según la preferencia del señor:

"Para esto de dar la copa suele no aver persona señalada, sino gusto del señor, a quien se la quiere pedir, y muchas vezes no pedirsela a nadie, sino pedirsela generalmente, $y$ traerla el que esta mas a mano, y assi es menester, que todos los of iciales de la casa la sepan dar."

El servicio de la copa a la señora de la casa debía ser con igual ceremonia que al señor, si acaso con mayores reverencias todavía, pues las buenas maneras de la época y las normas nobiliarias de relación exigían siempre mayor cortesía en el trato a las damas: "Y si el señor es casado, de la misma manera se le ha de dar la bevida a la señora, $y$ antes con mas reverencia que al señor, que a las señoras daseles siempre mas cortesia." $"$

El ritual de la bebida durante la cena todavía era más complicado, porque intervenian también las luces. Por una parte el gentilhombre de copa era el res-

\footnotetext{
76 Yelgo, 99v-100v.

"Yelgo, $101 \mathrm{r}$.

7h Yelgo, 100v-101r.

Telgo, 101r.

"Yelgo, 101r.
} 
ponsable de iluminar con hachas el parador donde estaban las bebidas y el traslado de la copa hasta la mesa, procurando que las hachas no hicieran demasiado humo, pues resultaba desagradable para los comensales:

“... y si fuere quando cena, y la reposteria o aparador estuviere apartado dos pieças de la mesa, hara (el gentilhombre de copa) encender dos hachas, que vengan delante la copa, y sino estuviere el aparador mas de una pieça mas atras, no es menester encendellas, porque assi como assi se han de quedar una pieça mas atras de la pieça donde cena el señor, porque no es bien hecho entrar con las hachas delante, y mas si la pieça es pequeña, el humo dellas suele dar fastidio, y quedadas las hachas entra la copa..."

Por otra parte, el maestresala se debía ocupar de levantar las velas de la mesa, con muchas ceremonias, para facilitar que el señor viera bien la copa en el momento de beber:

"Tendra cuydado (el maestresala) quando cene el señor, y pidiere de bever, de alçar uno una vela, y otro gentilhombre otra, que son la que estan en la mesa, y las tendran en el ayre mientras beve, y en acabando de bever haran una reverencia y levantaran las velas un poquito hazia arriba, y la assentaran en la mesa, haziendo una reverencia al compas del baxarlas, y mirar, que quando se asienten no se pongan mas atras, ni mas adelante, sino en su mismo asiento do estavan. ${ }^{182}$

El sentido ceremonial de la comida se intensificaba en caso de haber invitados, en diversos grados, de acuerdo con la categoría de cada uno de ellos. Pues el ritual, además de las normas básicas generales, tenía una serie de especificaciones, según la calidad de la persona a que hacía referencia. Entonces todos los criados debían estar presentes y el mayordomo debía acompañar a los convidados como muestra de especial consideración. También había de esinerarse en la etiqueta en el servicio de la mesa:

"Y quando viniere algun huesped, y alguna visita de cumplimiento, ha de avisar a todos los criados de la casa, para que se hallen presentes, y tambien lo ha de estar el. Y siendo persona, que sea necessario cumplir, han de yr con ella hasta la parte que les pareciere, conforme a la calidad de cada una. A los huespedes que huviere en la mesa se ha de servir, conforma a lo que se acostumbra hazer con cada uno, dando las ceremonias que le tocan." ${ }^{\text {\$83 }}$

\footnotetext{
${ }^{81}$ Yelgo, 99v.

.2 Yelgo, 37r:

${ }^{83}$ Yelgo, 5 v-6r.
} 
En el servicio de la mesa, como en todo, existían distancias entre el ideal y la práctica común. Aunque los pajes debían ser un dechado de perfecciones, la realidad era que el comportamiento de algunos de ellos dejaba, a veces, bastante que desear. Las críticas a las malas costumbres de los pajes mientras servían la mesa resultan muy reveladoras. Si Yelgo de Bázquez se molestaba en advertir contra esas malas costumbres, debía ser acaso porque no eran infrecuentes en algunas casas:

"... lo que yo se dezir, es, que no ay page que quiera se su voluntad tener este oficio: porque estan hecho un estafermo, y no alcança presa. Aqui ha de meter la mano el Maestresala muy de veras, y con grandisimo rigor, que mientras el señor come, que no coman los pages, mientras sirven a la mesa, que si alcançen algo, lo guarden para comerlo quando fueren a comer: porque no se puede sufrir el poco respeto que tienen, y es baxeza andar lamiendo platos, y para salir limpios a la mesa, se van limpiando en todas las colgaduras, que estan del aparador a la mesa, todas sirven de rodillas, limpiandose los hozicos para entrar a la mesa a coger otro plato, que dexó ojeado, para hazer lo mismo, que si huviese una pena, que quien comiesse mientras el señor comia, con rigor le echasen de casa, se remediaria tan mala costumbre. No digo mas desta desorden por no dar descontento al Lector con grosserias, que harto tenia que dezir, como es limpiarse en las faldas de la camisa, y otras cosas que callo al modo destas." ${ }^{\text {\$ }}$

Pese a todas las imperfecciones y contradicciones, el simple hecho de que hubiera quien se preocupara de escribir un libro sobre el "estilo de servir a Príncipes" ya dice mucho sobre el estilo de vida noble en la España del Siglo de Oro.

${ }^{84}$ Yelgo, 39r-39v. 